\title{
Contribuição
}

\section{para o tratamento convulsivante nos esquizofrênicos}

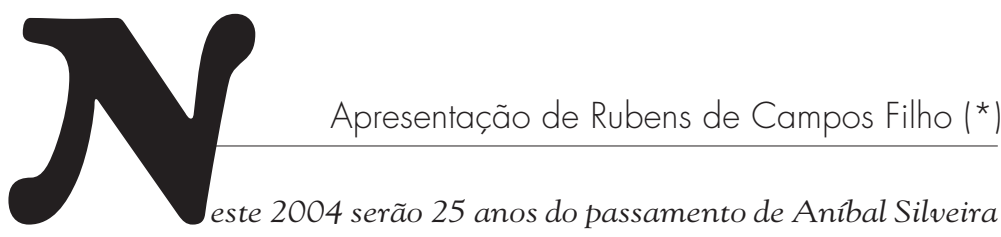

(17/3/1902 - 19/8/1979) para, como ele mesmo dizia, da vida objetiva para a subjetiva. Para nós que tivemos o privilégio de conviver e trabalhar com ele durante alguns anos, sua falta foi muito grande e até hoje não superada.

Talvez a sua grandiosidade diante da doença mental nos faça parecer menores ainda, conforme o tempo passa. Eminente professor, cujos textos em quaisquer línguas eram fáceis de ser digeridos, possuía uma capacidade de abstração tão grande que conseguia unir a um só tempo a psicopatologia de Karl Kleist com a Teoria de Personalidade de Augusto Comte.

Da mesma forma com que conseguia entender um paciente de simplicidade de raciocínio, entendia igualmente aquele outro com capacidades intelectuais brilhantes. Faz-nos falta não apenas o seu conhecimento, mas também o trato com que conduzia toda uma equipe. Sem se alterar, sempre com uma palavra de união e, principalmente, transmitindo a todos que perto dele estivessem o seu conhecimento científico.

O texto que reproduzimos a seguir é apenas um dos muitos que foram elaborados por ele. Por este e outros artigos que, esperamos, possamos publicar, daremos a todos aqueles que não tiveram a oportunidade, ou a sorte, de com ele conviver um pouco do seu conhecimento para que, no futuro, possam ter, como nós, a idéia de que Aníbal Silveira viveu toda a sua vida para desvendar a ciência psiquiátrica, para aqueles que queriam beber do seu saber e, principalmente, se doando integralmente a seus pacientes.

Ao prof. Aníbal a singela homenagem de todos os que com ele aprenderam simplicidade, honestidade, humildade e prazer no trato com a medicina psiquiátrica.

A ele nossa eterna gratidão e nosso obrigado. 


\section{TENTATIVA DE EXPLICAÇÃ̃O PARA OS RESULTADOS}

Com a presente iniciamos uma série de nove comunicações nas quais esperamos ter a honra de relatar aos prezados colegas os resultados de estudos que desde o ano passado vimos empreendendo. Tais estudos encontram-se ainda em andamento e, devido à multiplicidade dos fatos a coligir e aos numerosos tropeços que cumpre afastar para a apreciação correta dos fenômenos, não será possível dá-los por findos dentro de pouco tempo. Por isso, embora houvéssemos inscrito na ordem do dia esta primeira comunicação já em novembro de 1936, cedemos de bom grado a motivos independentes de nossa vontade, que nos obrigaram a retardar-lhe a apresentação.

Nossos trabalhos, a que aludimos, têm visado por ora tão-somente o método terapêutico proposto definitivamente por Von Meduna (133-136). Entretanto achamos acertado designá-los, no decorrer da contribuição pessoal que hoje encetamos, com o termo genérico de "tratamento convulsivante", ao invés de indicar o medicamento empregado para tal fim. E isso primeiramente porque o interesse precípuo recai sobre o tipo da terapêutica. Este não só constitui inovação real mas ainda, a nosso ver, inovação plenamente defensável à luz da patologia cerebral. O cardiazol em doses "supraterapêuticas" representa apenas um dos meios, por enquanto o mais adequado, para conseguir clinicamente tal finalidade. De resto, faz parte de nosso plano de trabalho, embora não com importância fundamental, experimentar outros meios medicamentosos clinicamente análogos ao pentametilenotetrazol.
Nessa grave questão da esquizofrenia, penosa principalmente pela inoperância geral da terapêutica, chamou-nos a atenção o método ideado por Von Meduna (134136). Dentre os demais processos de tratamento preconizados em data mais ou menos recente pareceu-nos o mais adequado para o ambiente hospitalar e o mais propício para aplicação em larga escala: além de exequiível, com notável simplicidade, não determina lesões no sistema nervoso central - segundo o demonstram a verificação experimental $(133,136)$ e os estudos clíni$\cos (69,105,111,194,205)$ - ao mesmo tempo que não oferece contra-indicações especiais (136). Além disso pode ser aplicado com proveito mesmo quando o quadro mórbido já data de alguns anos; e por isso que - segundo o nosso modo de ver põe diretamente em ação o dinamismo do córtex cerebral, torna dispensável a ação psicológica de ambiente a qual constitui fator importantíssimo em outros métodos $(10,25,41,42,46,87,146,170)$. Aliado a essas condições grandemente favoráveis, o alto contingente de remissões legitimamente atribuíveis ao emprego do método torna-o digno de ampla utilização. Ao passo que tais remissões montavam em 1935 (135) a 40\% dos casos tratados, já os resultados do próprio autor atingiam, quando da última publicação, a 54 remissões num total de 110 medicados (136), entre os quais alguns com 10 anos de doença e 26 acima de 5 anos (1). Semelhantes sucessos abrem largas perspectivas à terapêutica inaugurada por Von Meduna (2).

Naturalmente assiste sempre razão àqueles que, em tese, acolhem com ceticismo os resultados terapêuticos obtidos em esquizofrênicos: a imprecisão do conceito que sob o aspecto estritamente anátomopatológico, mas também sob o clínico e o patogênico, as diferentes escolas admitem com relação à esquizofrenia deixa sempre margem para dúvidas quanto à precisão diagnóstica e particularmente à interpretação das remissões (3). Em nosso meio essas dificuldades intrínsecas se acrescem de outras, devidas à deficiência geral de informes de família que precisem o tipo de per-
Comunicação apresentada à Associação Paulista de Medicina, Secção de Neuro-psiquiatria - e reunião de 5-VII-1937, e posteriormente publicado em: Arquivos da Assistência Geral a Psicopatas do Estado de São Paulo, ano II, no 2 São Paulo, 1937. Nesta edição, foi respeitado o padrão bibliográ fico do original. As remissões das notas estão em itálico.

Nas mãos de Von Angyal e Gyárfás o aludido método produziu, entre 27 pacientes tratados durante o 1o ano de do ença, 15 remissões ao todo e no conjunto total dos casos $45-23$ remissões (213).

2 Em carta recente (5-Vl-1937) aquele psiquiatra húngaro comunica-nos que investigadores como Georgi, Klaesi e o próprio Sakel a estão empregando em larga escala e com excelentes resultados.

Justamente essa a reserva externada por Enke (215) em artigo estampado no Fortschritte der Neurol und Psychiatrie, no de junho de 1937, e portanto chegado a nossas mãos após a apresentação do presente trabalho: "Particularmente nos casos 'recentes' e nas esquizotrenias paranóides' taz-se notar a fata de esclarecimentos mais pre cisos quanto ao diagnóstico diferencial. Tem-se a impressão de que as diferenças numércas-por vezes realmente grandes - dos resultados obtidos pelos diversos autores sejam devidas à diferença de critério diagnóstico, e de que as remissões 'devidas à terapêutica' assinaladas em percentagem particularmente alta se explicam pelo fato de entre os casos dessa modalidade se encontrar grande número que tal vez se curasse espontaneamene ou mediante outros métodos que mencionamos acima como aplicáveis" (p. 234). 
sonalidade anterior à doença, o modo de início desta, a precedência imediata ou remota de processos infecciosos. Nossos estudos padeceriam de vício fundamental se não considerassem previamente essas dificuldades e não as afastassem de maneira decisiva. Devemos pois assinalar que do cabedal clínico no qual se baseiam as nossas conclusões excluímos todos aqueles pacientes - embora de sintomatologia estritamente "esquizofrênica"-a respeito dos quais não conseguimos indicações precisas sobre os antecedentes pessoais e a história mórbida que precedeu imediatamente à internação. Na observação hospitalar procuramos reunir os dados objetivos tão minuciosamente quanto possível. Para atender a esses quesitos adotamos o seguinte critério sistemático: colhemos pessoalmente, junto à família do observando, os dados anamnésicos remotos e próximos; na documentação psiquiátrica recorremos ao teste psicológico de Rorschach, sempre que aplicável; mediante o tratamento desintoxicante e a piretoterapia excluímos previamente não só a possibilidade de remissão espontânea como a viabilidade de métodos terapêuticos de rotina; finalmente, para obtermos dados comparáveis, investigamos em cada paciente o quadro pneumoencefalográfico, o hematológico, além das reações biológicas completas no líquor. Neste último domínio faz parte de nosso programa, comoelemento fundamental para avaliar os resultados segundo o critério doutrinário que adotamos, a reação dos fosfatídios cerebrais proposta por LehmannFacius (113). Entretanto até o presente não nos foi possível pesquisá-la, apesar de todos os esforços envidados nesse sentido, mesmo antes de conhecermos na íntegra a comunicação (113) daquele autor (4). As manipulações relatadas na citada comunicação vêm indicadas apenas quanto à ordem de sucessão, sem outros pormenores indispensáveis; dessa forma faz-se mister longa e acurada experimentação prévia labor que o nosso prezado colega dr. João B. dos Reis está executando por nímia gentileza - para que a técnica seja estatuída em moldes de verificação sistemática.
Semelhante cuidado prévio constitui condição primordial para que os possíveis resultados se interpretem corretamente e não venham a falsear as conclusões quer no sentido otimista, quer no sentido oposto. É que se trata então de apreciar o valor de determinado método terapêutico em determinado grupo mórbido; e dessa mesma apreciação depende naturalmente o conceito prognóstico em relação à referida variedade nosológica, prognóstico geralmente sombrio no caso particular da esquizofrenia. Entretanto o fato de tratar-se de doentes realmente esquizofrênicos ou de esquizofrênicos apenas em aparência não infirma o modo de ação - segundo o entendemos do processo convulsivante, da mesma forma que não afeta a concepção segundo a qual, julgamos nós, pode encarar-se o dinamismo cérebro-patológico do quadro esquizofrênico. Somos dos que não acham censurável a expressão síndrome esquizofrênico $(138,141,155)$. Para nós a diferença essencial entre os diversos tipos da chamada esquizofrenia e as ocorrências patológicas superponíveis àqueles consiste em que no primeiro caso as desordens resultam de afecção primitiva do encéfalo ao passo que no segundo traduzem o modo de reagir ante condições mórbidas inicialmente extracerebrais. As demais características, por exemplo a predisposição hereditária (26), o tipo de personalidade $(65,117$, 162), por outro lado a incidência positivada de fatores extrínsecos, quer predominantemente exógenos $(59,125,138,184)$, quer de ordem moral $(19,107,178)$, tanto podem interferir em uma como em outra das eventualidades patológicas há pouco lembradas; não servem pois, per se, como elemento diferencial.

Se as controvérsias nos diferentes aspectos da esquizofrenia vêm de longa data e assumem maior intensidade no campo do substrato anatômico, cabe aos dois mais recentes processos terapêuticos-o do choque insulínico e o das convulsões provocadas - o mérito de evidenciar quanto são insuficientes aqueles diversos critérios para a demarcação das formas de esquizofrenia e mesmo, genericamente, dessa pretendida 
“entidade" nosográfica. E mais, segundo nossa opinião pessoal, o de frisar eloqüentemente que a interpretação útil e fecunda dos vários tipos esquizofrênicos é a que se norteia pelas localizações encefálicas e não a que se limita ao aspecto estritamente histológico. Esta se refere exclusivamente a um dos tipos, o lesional, e assim mesmo não se isenta de contestações. Aquela, ao contrário, permite compreender o aludido tipo nas próprias manifestações clínicas e além dele as diferentes modalidades de repercussão e de reações episódicas, com sintomatologia esquizofrênica. Certamente entendemos as localizações como discriminação areal de grupos celulares a que correspondem funções psíquicas simples mas os quais integram sistemas organológicos cujas funções complexas subentendem a harmonia funcional das diversas porções encefálicas (5).

Oexame clínico aprofundado dos esquizofrênicos quanto aos distúrbios psíquicos essenciais e aos que destes derivam por dinamismo mais ou menos complexoe, por outro lado, a análise de estudos clássicos relativos à esquizofrenia, tais comoos de Bleuler (21), Gruhle (65, pp. 135-210), Jelliffe (79), Mayer-Gross (132, pp. 293594), Minkowski (139), permitem fundir em três tipos principais os diferentes fenômenos esquizofrênicos. No primeiro as desordens psíquicas primárias seriam no setor da atividade; em outro as perturbações seriam primariamente intelectuais; finalmente no terceiro apareceriam como primários os distúrbios afetivos. Em todos esses tipos porém o colorido psicológico fundamental, esse que autoriza a grupar todas as variantes mórbidas em torno de um quadro comum, são as perturbações da atividade, conforme logo diremos; e mesmo, em grande proporção dos casos concretos, talvez a maioria, representam elas a alteração primitiva.

Empregamos a distinção abstrata entre distúrbios primários e secundários não precisamente como o faz Mayer-Gross (131), que a entende como relativa a fundamental e acessório, porém antes no sentido de transtorno originário e transtorno de repercus- são, conforme exemplifica Bleuler (21). Entretanto a avaliação relativa dos fatos psíquicos é aqui estabelecida segundo análise mais aprofundada que a do psiquiatra de Zurique por isso nas próprias funções complexas - em estado normal - distinguimos as funções simples integrantes, como em relação a outras, mesmo irredutíveis, procuramos as demais que as regem ou, ao contrário, que delas dependem. Certamente tal critério não é nosso; representa mera aplicação prática da doutrina cerebral de Augusto Comte, quando não se trate de princípio explicitamente estabelecido pelo filósofo ou por seu eminente discípulo Georges Audiffrent (9). Convém por isso definir os termos antes de entrarmos no dinamismo patológico ao qual nos referimos.

Por atividade, no sentido de que acima fizemos menção deve entender-se o conjunto de disposições subjetivas que levam o homem a atuar sobre o mundo exterior. Cumpre aí distinguir em um grupo a iniciativa ou empreendimento - cuja expressão mais típica é a coragem-e a tendência para refrear ou reter os impulsos, que constitui a prudência; e de outro lado a manutenção do estímulo, qualquer que seja o campo onde se desenvolva - a perseverança. As duas primeiras compõem a atividade propriamente dita e, além das correlações com os atributos intelectuais e os sentimentos, regem diretamente o exercício do aparelho muscular; a terceira, que torna possível a harmonia e a continuidade de ação das precedentes, exprime a firmeza. Funções elementares de significação diversa, somente podem ser desempenhadas por órgãos distintos.

Não nos é possível analisar aqui as interdependências de tais atributos psíquicos nem o dinamismo deles no conjunto das funções encefálicas; mas o nosso modo de considerar a patologia cerebral, mormente quanto aos distúrbios "esquizofrênicos", ficaria incompreensível se não referíssemos os dados essenciais a esse respeito. Como fizemos notar em outra comunicação (O) a situação intermediária dessas qualidades práticas em relação às funções de inteligência e aos instintos faz com que a elas caiba imprimir ao indivíduo o cunho

\footnotetext{
5 "As Funções do Lobo Frontal" in Rev. de Neurol. e Psiquiatria de S. Paulo, 1, 196-228 1936; "Campos Arquitetôncos do Lobo Frontal e Funções da Inteligência", Com. d̀ Assoc. Paulista de Medicinadezembro de 1934 la sair na Rev. de Neurol. e Psiquiatria de S. Paulo, 1937) - "Lesões Casuais e Lesões Sistemática do Cérebro nas Doenças Mentais", in Arq. da Assist. a Psico patas, S. Paulo, II, 191-227 1937

6 "Teoria das Funções Cerebrais Segundo Augusto Comte. Apa nhado Geral". Com. à Assoc. Paulista de Medicina, Seccõa de Neuro-psiquiatria, em reu nião de 5-XI-1936.
} 
distintivo - o que explica a designação de caráter com que as denomina Augusto Comte. Porém cada uma delas interfere a seu modo no conjunto cerebral. A coragem, que determina a iniciativa prática, regula na esfera intelectual principalmente a contemplação - de preferência a observação abstrata -, a capacidade dedutiva e, secundariamente, a expressão; atua sob o impulso dos instintos mais personalistas: em primeiro plano o destrutivo e por intermédio deste o da conservação individual; secundariamente o orgulho e, ainda menos diretamente, o da construção. A manutenção da atividade exterior compete à perseverança, a qual coordena também as funções de contemplação, mas principalmente as de elaboração intelectual ativa (sobretudo a indução) e ainda a expressão; estimulam-na de preferência os atributos afetivos superiores - os da sociabilidade e dentre os egoísticos mormente o de construção e a vaidade. Finalmente entende a prudência com a retenção ou o refreamento da atividade, o que pode - nos casos de predomínio patológico - levar à completa inação; esse atributo prático liga-se de modo quase exclusivo à esfera afetiva, que o incita principalmente mediante o instinto de conservação individual, o de construção e também o de posse; não repercute no campo da inteligência senão de modo indireto, por intermédio da reação sobre os demais sentimentos.

Os órgãos encefálicos que desempenham semelhantes funções mantêm com os demais e principalmente entre si conexões fisiológicas reconhecíveis pelas afinidades de estrutura e pelas vias de associação. "Em razão da propriedade em comum de estimular os órgãos cerebrais ou de enervação com os quais mantêm relação", diz Audiffrent (9), “os três órgãos da ativi-

7 Das Funções Cerebrais.

8 Ver: "Síndromo de Automatismo Mental de Clérambault", I e || in Rev. de Neurol. e Psiquiatria de S. Paulo, vol. 1, 374-389 1935; vol.ll, 1-31, 1936. " $\mathrm{Va}$ or Semiológico do Automatismo Mental. Comentários em Torno de Alguns Casos", in S. Paulo Médico, X, II, 67-80 1936 aprofundar a análise psicopatológica nos casos clínicos, mormente os de lesão cerebral em foco, e torna possível, por outra parte, identificar mediante a investigação anátomo-clínica os órgãos encefálicos aos quais segundo a escola positivista correspondem semelhantes funções subjetivas.

Com referência aos fenômenos esquizofrênicos fundamentais essas diferentes funções aparecem perturbadas, segundo há pouco dissemos, por modalidades diversas; daí os três tipos a que aludimos e que se poderiam resumir da seguinte forma sob o aspecto psiquiátrico.

No primeiro as desordens fundamentais, primitivas na acepção a que acima referimos, são as do empreendimento prático, o qual tanto pode surgir deficitário de maneira global como traduzir-se pela versatilidade improdutiva. As alterações intelectuais e as instintivas advêm da falta de regência por parte da atividade. Assim, na esfera da inteligência aparecem o autismo por deficiência de espontaneidade, a falta de iniciativa para raciocinar, o mutismo devido à carência de iniciativa; como desordens intrínsecas surgem apenas perturbações sensoriais, quer como automatismo mental de Clérambault, seja de tipo motor, seja do auditivo verbal ou do verbal-motor, quer como alucinações auditivas propriamente ditas: num caso e noutro porém tais fenômenos indicam justamente a participação do sentido muscular, consoante procuramos evidenciar baseados em observações clínicas pessoais (8). Os impulsos afetivos assumem a aparência de embotamento; quando se exteriorizam alterações nesse domínio denunciam elas a participação do instinto de destruição - o qual se reflete também na mordacidade, nos remoques, no tom irônico das respostas -, o nutritivo, o orgulho; em todo caso as perturbações da afetividade não se impõem como predominantes. Por vezes o embotamento da iniciativa se acompanha de instabilidade e exuberância de motilidade; as ações se mostram interrompidas por movimentos paradoxais, como que desvirtuadas pela paracinésia. Não raro entram então para o cortejo sintomático perturbações 
cenestésicas mais ou menos acentuadas, possivelmente com desorientação sobre o próprio corpo; explicações delirantes de tipo egocêntrico, sempre mal sistematizadas, externadas reticentemente, deixam transparecer ao mesmo tempo a consciência do estado mórbido, a falta de subordinação das concepções ao mundo objetivo e o excesso de prudência; com referência à expressão, fazem-se notar estereotipias de gestos, trejeitos, momices, estereotipias gráficas, alterações da elocução verbal assimiláveis à parafasia. Ainda outra modalidade de ocorrência, essa em que a redução de empreendimento se agrava com os fenômenos de catalepsia; é possível por vezes surpreender também, nessas condições, distúrbios intelectuais por insuficiência de observação abstrata, que determinam então impossibilidade para reproduzir gestos expressivos e objetivar construções quaisquer - tal o que sucede na "apraxia construtiva" - e para avaliar as relações cronológicas; à perseveração de atitudes e de posição, característica desta variedade catatônica, se juntam, conforme as circunstâncias, reiterações de tipo palilálico ou paligráfico, neologismos, amaneiramento de mímica ou de elocução verbal; as concepções delirantes - com os caracteres gerais há pouco relembrados - traduzem a participação dos instintos; e não só os da personalidade propriamente - o de construção, de posse, de nutrição, a vaidade mas também o apego e a veneração. Cabe notar ainda que estas duas modalidades de distúrbios da iniciativa - a catatônica hipercinética e a hipocinética - podem alternar-se no mesmo doente.

Na segunda variedade principal podem anotar-se também as três ordens de fatos paralelos que aí acabamos de mencionar. Entretanto algumas particularidades permitem admitir como intrínsecas as desordens da inteligência: primeiramente predominam de maneira nítida as contradições alógicas, na acepção de Kleist $(88,89)$; os transtornos intelectuais assumem ao mesmo tempo os característicos do síndromo frontal; as perturbações perceptivas por um lado, as concepções delirantes por outro, conquanto conservem os traços fundamentais anteriormente referidos, passam entretanto para segundo plano.

Enfim os distúrbios das mesmas funções cabem no terceiro tipo quando assumem aspecto grave com relação ao campo afetivo. Também aqui não é difícil apreciar a seriação paralela dos fenômenos mórbidos que no domínio da atividade e no da inteligência correspondem aos transtornos primitivos. Entre estes a sitiofobia, e a espurcícia indicam o profundo comprometimento do instinto de conservação individual, da mesma forma que o predomínio excessivo do instinto destrutivo se traduz na agressividade, na destrutividade, e a exaltação do instinto sexual transparece nas atitudes eróticas e, associado à vaidade, no exibicionismo; tais tendências impulsivas vão repercutir no comportamento práticoanalogamente ao que antes dissemos - ora determinando o embotamento global da iniciativa, ora a agitação motora descoordenada; e na esfera intelectual vão indiretamente originar as mesmas conseqüências que procuramos analisar no primeiro tipo. Em outras eventualidades seriam o medo, as atitudes de defesa ou então as tentativas de suicídio - canhestras e aparentemente imotivadas - , os indícios de desvio mórbido quanto ao instinto nutritivo, como o colecionismo para com o de posse; componentes estas que iriam influenciar no sentido do negativismo, das hesitações, da ambivalência à atividade prática; como consequiências de tipo intelectual as alucinações cinestésicas ou mesmo parestésicas - na acepção de estranheza ou de desorientação para com o próprio corpo -, a incapacidade de identificar a personalidade subjetiva, entram para a mesma série de distúrbios, de modo semelhante ao que já referimos; embora fenômeno de ordem intelectual, a elaboração delirante denuncia por vezes as alterações de sentimentos quer pelo egocentrismo, pelo teor persecutório, pelos temas de referência a si (Wernicke), de grandeza ou de ciúme, quer pelas idéias abstrusas de reforma social; ainda no âmbito da inteligência ocorrem nãoraro, neste grupo, distúrbios perceptivos 
visuais como ilusões, fenômenos do chamado "mentismo representativo" (Clérambault) e talvez alucinações propriamente ditas. De qualquer forma a participação primária dos motores afetivos é aqui marcada profundamente pela ruptura brutal para com o mundo objetivo e ainda pela tendência ao aspecto demencial quando não para a demência na acepção adequada do termo. A este terceiro tipo, quando os distúrbios primários resultam de alterações anatômicas, corresponde certamente na íntegra o quadro denominado "demência precoce".

Naturalmente só aludimos, nesses três grupos abstratos, aos fenômenos psíquicos fundamentais ou, melhor dito, correspondentes a funções cerebrais diretamente interessadas no processo mórbido. Porém cada um desses distúrbios pode repercutir sob várias modalidades no conjunto dos atributos subjetivos, o que depende da organização psíquica individual no estado hígido. Ademais as diversas funções psíquicas aí referidas correspondem a órgãos encefálicos distintos, segundo dissemos. É possível assim, mediante a análise dos casos clínicos adequados, identificar as zonas corticais respectivas. E realmente os dados anátomo-clínicos coligidos já em número avultado permitem estabelecer as correlações anatômicas mesmo nos casos de esquizofrenia, como o fazem por exemplo Von Angyal (6) ou Bychowski (30). Segundo o nosso modo de encarar a patologia cerebral $(181,182)$, os três tipos que procuramos esquematizar correspondem, no plano anatômico, respectivamente aos tipos parieto-temporal, frontal e parietooccipital. É preciso considerar ainda, com relação ao processo patológico em si, que os desvios de função podem advir de alterações meramente dinâmicas nos órgãos correspondentes, as quais em regra precedem de muito tempo ao conseqüente desmantelo histológico. Teremos então a considerar em cada sistema de órgãos as seguintes eventualidades: a) os transtornos, qualquer que seja a localização das áreas encefálicas correspondentes, resultam apenas de desvio funcional; b) as áreas que ao exame clínico se denotam como primari- amente atingidas exibem alterações estruturais porém as de repercussão não as revelam;c)é possívelevidenciarocaráter lesional em todas as zonas cerebrais cujas funções se mostram perturbadas (182); esta particularidade depende aliás do tempo de doença e da maior ou menor capacidade de resistência - isto é, da menor ou maior miopragia dos órgãos cerebrais considerados.

Essas diferentes possibilidades, admissíveis em tese, ainda podem complicar-se nos casos concretos pela eventual ocorrência de processos infecciosos que repercutem sobre a estrutura encefálica. Isso esclarece as divergências de conclusões dos investigadores quanto ao substrato lesional nos pacientes esquizofrênicos; porém não invalida a opinião dos que atribuem valor patogênico a certos tipos de alterações celulares, conforme recordaremos rapidamente.

Segundo Josephy (80), foram Alzheimer e Sioli os primeiros a evidenciar alterações arquitetônicas no cérebro de esquizofrênicos. O primeiro deles relacionava a tais desordens anatômicas o embotamento anotado clinicamente. O segundo chamava atenção - em um caso de excitação catatônica prolongada por 5 anos - para lacunas celulares, em forma de manchas, limitadas notavelmente à parte superior da quarta camada cortical. Josephy precisa o significado das alterações finas - a que chama respectivamente pequenas lacunas, focos destrutivos e falhas celulares difusas - de estrutura celular do córtex em doentes da chamada demência precoce. Além dessas destruições neuronais, a participação da neuróglia se patenteia por desordens tróficas de caráter progressivo ou sob aspecto degenerativo, bem como entre as próprias células nervosas ganglionares se manifestam perturbações nutritivas reconhecíveis histologicamente $(80,81)$.

Depois de descrever os caracteres do processo atrófico celular, mostra Miscolczy - o que em parte fora feito por outros anatomopatologistas - que em profundidade as camadas corticais são atingidas na seguinte ordem decrescente quanto à intensidade: III, V, VI, II, IV; e considera leve o com- 
prometimento do córtex quando apenas a camada III aparece lesada. Quanto à extensão em superfície, lembra que ambos os hemisférios são interessados de modo aproximadamente igual. Frisa porém o fenômeno singular de aparecerem "certas áreas intensamente atingidas pelo processo, ao lado de outras poupadas". E noutro ponto, após evidenciar as lesões que não devem considerar-se por não serem intrinsecamente filiáveis à variedade mórbida em questão: “Ao legítimo síndrome esquizofrênica de base endógena corresponde um processo necrobiótico das células nervosas, principalmente as do córtex cerebral, em conseqüência do qual aquelas - seja isoladamente, seja em grupos - adoecem e mais tarde desaparecem. Processo atrófico das células nervosas e lacunas na seriação celular-ademais bem ordenada - da arquitetura cortical, contituem pois em primeira linha os sinais apreciáveis (verwertbaren) da afecção cerebral esquizofrênica" (141, p. 204).

A seu turno diz Fünfgeld: "Sempre considerei como substrato do surto agudo a alteração de aparência atrófica das células ganglionares, processo destrutivo (Anflösungsprozess) peculiar, que evolve de modo crônico e que evidentemente pode deter-se em qualquer estádio. Encontra-se, nos casos antigos, sob as mais diversas modalidades, muitas vezes em ocorrência recente e antiga, lado a lado. As lacunas no córtex constituem problema dificílimo. Justamente nos casos mais antigos podem eventualmente faltar, de modo notável. Segundo minha experiência são mais seguramente evidenciáveis nos casos em que a doença perdurou por 8 a 10 anos. Quanto mais velho o caso, tanto menos caraterístico o achado. Em geral o caso recente é bem reconhecível, contanto que doenças somáticas não mascarem os dados anatômicos. Há cérebros com lacunas muito pronunciadas e insignificantes alterações de tipo atrófico e ao contrário outros com grave atrofia e raras lacunas" (58, p. 233).

Naturalmente não se prestam para conclusões anátomo-clínicas casos em que à síndrome esquizofrênica poderia atribuir- se a encefalite do tipo da de Marchand, a qual geralmente se acompanha de processos celulares "degenerativos"; e temos a impressão de que dessa natureza são os pacientes estudados por D'Hollander e colaboradores (78). Também é o que ocorre com a intoxicação guanidínica, segundo o demonstram experimentalmente Sanz Ibañeze Rodriguez Perez (171). Finalmente seria indispensável excluir a possibilidade de alterações corticais conseqüentes a lesões situadas em outras porções do encéfalo, postas em evidência, entre outros, por Agostini (2); e também as ocasionadas por distúrbios circulatórios, como as assinala Spielmeyer $(185,186)$. Mas justamente por isso merecem fé as observações dos autores que acima citamos, pois indicam explicitamente e de modo probante haver selecionado sob critério rigoroso os casos de esquizofrenia.

O mesmo raciocínio, em ordem paralela de idéias, mostra que não assiste razão integral aos que pretendem negar valor àqueles estudos anátomo-clínicos. Assim, o indivíduo mentalmente são pode ter contraído toxi-infecções ou intoxicações dessas que freqüientemente danificam as células encefálicas, sem que tenha por isso apresentado necessariamente perturbações mentais pelo menos duradouras; nessas condições a investigação arquitetônica em cérebro de pessoas normais, como a fez Von Economo, poderá revelar lacunas análogas às que vimos referindo. Com maior probabilidade é de esperar-se ocorram elas em doentes mentais não esquizofrênicos ou em indivíduos anti-sociais (177). Entretanto as pesquisas neste último grupo de pacientes fazem com que Peters (153) conclua explicitamente não haver substrato anátomopatológico caraterístico para a esquizofrenia. Relata ele as investigações histológicas pessoais procedidas no cérebro de 7 sentenciados executados. Em todos, com a mesma técnica de Fünfgeld relativa a esquizofrênicos, evidenciou: "formação de lacunas no córtex cerebral, interpretáveis como falha local de células; falhas celulares difusas, alterações de células ganglionares". E depois de arrolar numerosas cau- 
sas de erro que podem influir na comparação de estruturas celulares conclui considerando "ainda absolutamente inseguro o substrato anatômico da esquizofrenia” (p. 329). Análogo juízo expendem Spielmeyer (188) e Steiner (190), o qual se baseia nos caracteres "organotípicos", "homotípicos" e "histotípicos".

Por certo estas considerações são endossáveis no que se referem ao significado intrínseco das alterações anatômicas referidas. Ressentem-se porém da orientação unilateral. Considerados os fatos sob luzes mais amplas como as que orientam as concepções de C. e O. Vogt (202) ou mediante o cotejo da superfície lesada (177), é possível colocar em paralelo a expressão clínica e o distúrbio anatômico. Aliás a observação anátomo-clínica de Dimitrie Victoria (36), os estudos minuciosos de Hechst (73, 74), os de Hedenberg (75), de Somogyi e Von Angyal (184), principalmente os de Fünfgeld $(57,58)$ e de Miscolczy $(140,141)$ não deixam dúvida quanto à legitimidade de tal aproximação de fatos. Para o nosso modo de ver apresentam particular interesse os dados anátomo-clínicos de Fünfgeld e de Miscolczy, que por isso analisaremos embora em breves traços.

O esquizofrênico de Fünfgeld, observado durante anos, "apresentara o primeiro surto aos 28 anos, o segundo aos 31 e o terceiro, no qual faleceu, aos 33 . Vivia fora de hospital sem denotar nada de estranho, mas escondia um sistema delirante de elevação e salvação, que revelava unicamente para Fünfgeld. Não se encontrou o menor indício de processo agudo em relação ao terceiro surto, mas havia lacunas focais muito nítidas e os conhecidos estados finais da atrofia. Era notável sobretudo nos campos temporais e parietais a descontinuidade demonstrada por Miscolczy" (58, p. 23 - grifo nosso). Chamamos a atenção para duas ordens de fatos paralelos: consciência de estado mórbido e conseqüiente dissimulação dele, portanto integridade intelectual, porum lado: anatomicamente nenhum distúrbio arquitetônico frontal; por outro, sistema delirante com tema relativamente elevado embora de cunho personalista: no plano histológico, predominância das lesões finas na zona parieto-temporal.

O aprofundado estudo de Miscolczy, vazado em moldes anátomo-clínicos precisos, merece apreciação cuidadosa. É possível, em todos os 13 casos esmiuçados, confrontar as funções psíquicas primariamente atingidas e as áreas corticais predominantemente lesadas: as "cartas" histológicas levantadas em relação a cada doente representam para isso elemento de extraordinário valor. Convém notar, no conjunto dos casos, algumas séries de correlações, por isso que a sintomas clínicos não peculiares ao quadro habitual correspondiam lesões em áreas via de regra poupadas pelo processo. Assim, em um caso em que havia perturbações da bexiga e do intestino grosso aparecia lesada a parte posterior do lóbulo paracentral; em outro, com parestesias e alucinações de órgãos internos, verificava-se desarranjo no giro central posterior; em outro ainda, que denotara astasia-abasia, evidenciou-se grave lesão no campo FB, de Von Economo. A correlação anatômica, apreciada no conjunto dos casos, é entretanto muito mais expressiva quanto à distribuição topográfica das alterações estruturais observáveis no cérebro de esquizofrênicos. A carta-resumo, relativa aos 13 casos, exprime a freqüência das lesões segundo as zonas corticais. Reproduzimo-la (Fig. 1) para evidenciar que também em condições mórbidas se salienta a correspondência funcional das zonas parieto-temporal, temporal e frontal.

Se portanto, como aliás acentua explicitamente Miscolczy, as alterações qualitativas não exprimem per se o processo, a ocorrência delas em número suficiente para aniquilar a capacidade funcional das áreas correspondentes representa indiscutivelmente a origem imediata do sintoma clínico. Nesse sentido é que entendemos a filiação direta dos distúrbios psíquicos às lesões finas do córtex encefálico. É aliás o mesmo argumento que nos leva, em contrário às conclusões de Lemke (115) ou de Almeida Prado (4), por exemplo, a admitir valor semiológico para as investigações pneumoencefalográficas. Não entraremos 


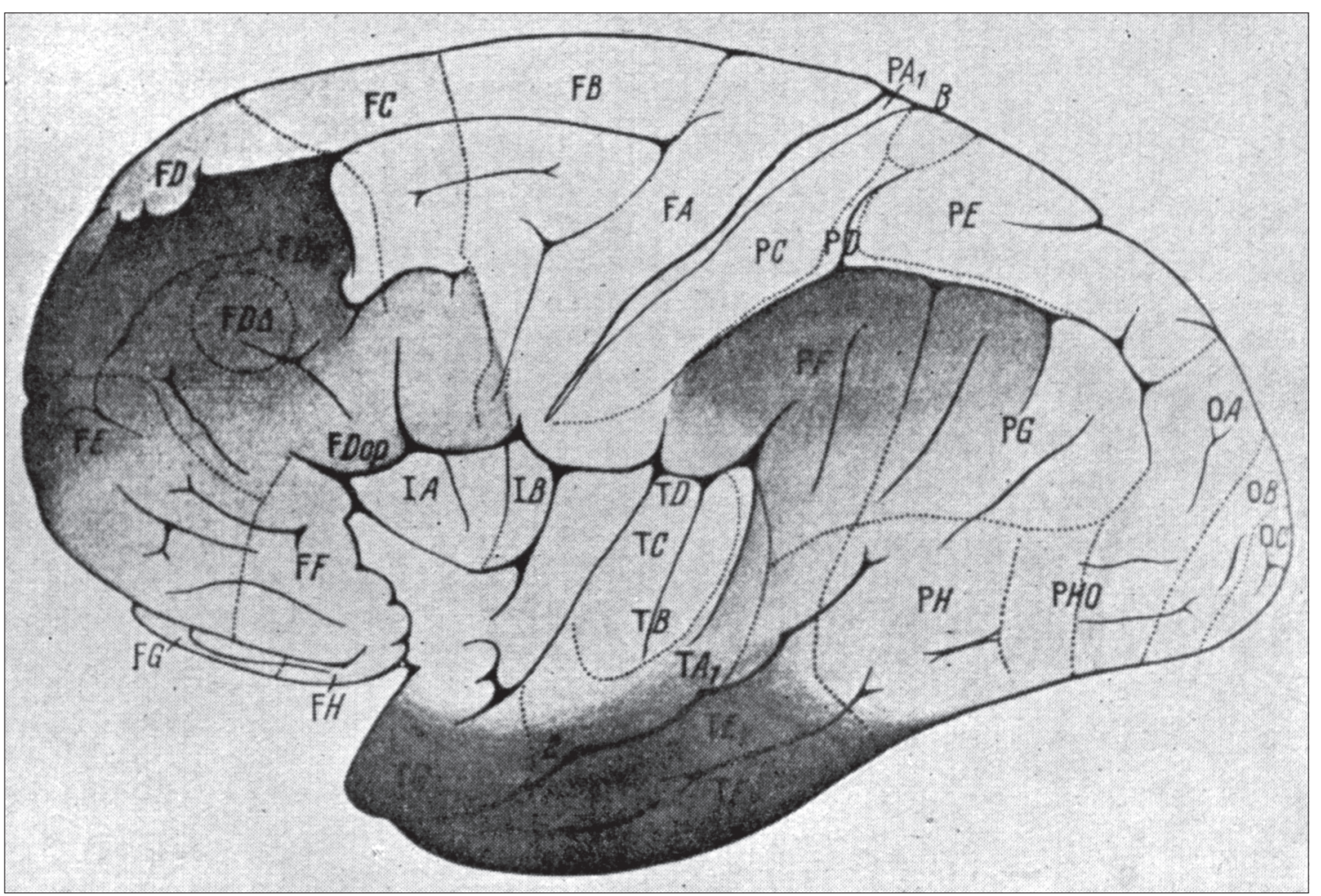

Figura 1 - Segundo Miscolczy. Distribuição topográfica das lesões cerebrais em esquizofrênicos. Carta-resumo relativa a 13 doentes. A intensidade da coloração exprime proporcionalmente a freqüência das alterações anatômicas.

por ora nessa questão, que será discutida em outra comunicação da presente série. Realmente Pendergrass (151), em um sentido, Kisimoto (86), em outro, evidenciaram as correlações entre certos sintomas clínicos e certos pormenores da pneumoencefalografia. E nós mesmos temos em numerosos casos clínicos obtido por esse exame semiológico a ratificação de localizações que psiquiatricamente havíamos deduzido com precisão (9). Quanto à significação dos sinais radiológicos obtidos pela insuflação de ar diremos na aludida comunicação; mas a concordância deles com os sintomas clínicos autoriza a emprestar-lhes valor, quando criteriosamente ajuizados uns e outros - frisemos bem.

Ora, aproximando as duas ordens de fatos - sintomas psiquiátricos fundamentais, lesões areais predominantes - vemos que as últimas correspondem às zonas encefálicas nas quais segundo a escola do método sub- jetivo (181) se localizam os órgãos correspondentes aos primeiros. Os três tipos de fenômenos esquizofrênicos podem aliás ser identificados na própria literatura anátomoclínica, o que aliás por vezes decorre de diferenciações explícitas dos próprios autores, como é o caso de Von Angyal (6), de Küppers (107), entre os que conhecemos.

Em suma, segundo o nosso modo de ver, o feitio clínico do quadro esquizofrênico é dado pelo comprometimento dos órgãos cerebrais. Passa para plano secundário indagar se se trata da forma "genuína" ou de modalidade de repercussão, na acepção que expusemos de início. Também pouco importa diferenciar do tipo "lesional” legítimo os tipos esporádicos - por encefalite da variedade de Marchand ou de outras modalidades - embora seja isto às vezes possível mediante o aspecto propriamente histológico das alterações anatômicas. Ao contrário, o que importa para a prática psiquiátrica - e
9 Ver: "Síndromo do Lobo Frontal. |Observações Clínicas com Verificação Pneumoencefalográfica)", in S. Paulo Médico VIII I, 167-193, 1934; "Lesõe Casuais e Lesões Sistemáticas do Cérebro nas Doenças Mentais", in Arquivos da Assist. Geral a Psicopatas, S. Paulo 11, 191-217, 1937: "Campos Arquitetônicos do Lobo Frontal e Funções da Inteligência", Com. à Assoc. Paulista de Medicina, dez./1934 la sair na Rev. de Neurologia e Psiquiatria de S. Paulo, 1937) 
importa de maneira fundamental, como procuraremos mostrar-é poder, antes de tudo, distinguir as funções psíquicas primariamente perturbadas; e, em seguida, avaliar se os respectivos distúrbios provêm de mero desarranjo dinâmico ou de alterações irremovíveis, estruturais.

Acreditamos que em relação à análise dos fenômenos esquizofrênicos sob a luz da patologia cerebral podemos repetir a observação de Minkowski (139, p. 250) quanto à fecundidade da noção de esquizofrenia. Realmente: estabelecido no caso clínico o diagnóstico de esquizofrenia "genuína”, isto é, afastada toda hipótese de reação psicogênica ou de qualquer modo sintomática, estava o psiquiatra desprovido de meios para intervenção ativa sobre os distúrbios intrínsecos. Justamente por consistir em doença primariamente cerebral os recursos terapêuticos aí utilizáveis se mostravam aleatórios, salvo o da narcose prolongada, que permitia, nos casos adequados, atuar sistematicamente mediante a influência moral $(25,47,87,124,146,179)$. Dentre os métodos propostos mais recentemente, dois inaugurados na prática há perto de 3 anos ampliaram porém de maneira até há pouco imprevista as possibilidades de ação. Referimo-nos ao choque insulínico e às convulsões provocadas pelo emprego do cardiazol em doses "supraterapêuticas". Não obstante, agem ambos -o de Sakel e o de Von Meduna - segundo dinamismo acentuadamente diversoe, para fornecerem toda a eficiência de que se mostram capazes, demandam prévia seleção dos casos clínicos. Nem o modo de agir de cada um desses processos terapêuticos nem a discriminação dos tipos mais adequados para o tratamento encontramos até o presente na já extensa literatura respectiva; entretanto o exame da questão sob o aspecto da dinâmica cerebral permite, segundo vamos expor, aventar hipóteses precisas a tal respeito, orientando assim as pesquisas nessa direção fundamental (10). Vejamos porém previamente, para cada método, a explicação proposta pelo próprio autor; e comecemos pelo tratamento insulínico.
Parece-nos admissível assimilaro método de Sakel ao de ação convulsivante, principalmente porque os fenômenos motores que põem em evidência podem entrar para tal série e porque eventualmente chegam mesmo a assumir tais caracteres. Ademais a finalidade de seleção para tratamento indica-nos como útil semelhante aproximação.

Sakel $(169,170)$ externa como hipótese de trabalho a de que os fenômenos mórbidos resultariam de alterações profundas na intimidade das células nervosas; o influxo nervoso seguiria nestas as vias filogeneticamente mais antigas e normalmente deixadas à margem por inadequadas para os processos fisiológicos. Justamente essas vias patologicamente reativadas seriam então bloqueadas pelo choque hipoglicêmico, de ordem vagotônica: donde restauração das vias normais para o fluxo, fixada depois por essa espécie de reeducação.

Tal concepção procura explicar os fenômenos íntimos que se passam nas células nervosas, quer em condições mórbidas, quer durante a ação terapêutica; porém não basta para esclarecer os transtornos variadíssimos, fartos de indicações patológicas, desencadeados durante as diversas fases do tratamento.

Semelhantes fenômenos variam quanto à expressão clínica e mesmo quanto à gravidade conforme o período considerado. Não nos demoraremos ao apreciar os dos primeiros momentos após a ministração da insulina. São eles descritos por todos os numerosos autores que se têm ocupadocom o processo. Recordaremos somente que os primeiros sintomas, quer viscerais, quer neurovegetativos, mesmo alguns de repercussão psíquica assumem aspecto idêntico ao daqueles que sobrevêm durante as crises espontâneas de hipoglicemia. Surgem depois fenômenos indicativos de alterações no mesencéfalo e no diencéfalo, tais como os circulatórios, os de sudorese e de salivação, os relativos à temperatura do corpo, os que se referem à morfologia do sangue e finalmente os que entendem com o metabolismo dos hidratos de carbono. Neste particular releva assinalar que a instalação 
do coma não depende diretamente da taxa glicêmica, segundo o assinalam vários pesquisadores e principalmente Yahn e Arruda (211). Tal fato corresponderá pois ao esgotamento da reserva de glicose nos tecidos, esgotamento que a nosso ver constitui a fase de atuação direta da insulina sobre o mundo subjetivo. À medida que se instala o coma surgem então fenômenos neurológicos e psíquicos de significação localizatória precisa e que, segundo entendemos, denunciam as diferentes zonas encefálicas em que se estabelecem as repercussões fisiológicas mesmo no estado normal.

Esses fenômenos motores são magistralmente estudados na memorável monografia de Von Angyal (7). Desenrolam-se em 6 fases, cujos caracteres gerais transcrevemos abreviadamente:

I - a) estado de excitação semelhante à moria, euforia, irritabilidade;

b) agitação motora.

II - ou de transição: sonolência, leve hipotonia, modorra.

III - a) lesão piramidal incipiente, abalos clônicos, anomalias de reflexos, de tônus, de atitude; movimentos primitivos com a boca; preensão forçada; b) sopor, movimentos espontâneos, como abalos faciculares e coreiformes; distribuição cruzada do tônus; desaparecimento dos movimentos primitivos com a boca; c) espasmos gerais de torção, de direção unitária, espasmos piramidais; acessos de tremor; desaparecimento da preensão forçada.

IV - desaparecimento dos movimentos espontâneos; espasmos de torção dissociados;

V - diminuição do tônus e dos reflexos; desaparecimento dos reflexos patológicos;

VI - coma profundo com arreflexia; desordens respiratórias e cardíacas de tipo bulbar; convulsões gerais com prevalência dos fenômenos de extensão (p. 52).

Segundo evidencia, as alterações da consciência "ocorrem durante o choque segundo a direção: irritação - sonolência sopor - coma”; explica-as pela “alteração funcional do centro do sono de Economo", primeiro indiretamente, mediante o exacerbamento da inibição cortical, depois pela lesão celular devida à hipoglicemia (p. 69) . Evidentemente nem todos esses fenômenos são de ordem motora: os de natureza psíquica aparecem aí de modo saliente. A todos esses distúrbios admite Von Angyal como expressão de alterações nos campos 10, 46, eventualmente o 9, de Brodmann, e o faz com redobrada razão, quanto às componentes neurológicas propriamente. Entretanto os sintomas de moria, euforia, irritabilidade, agitação psicomotora, não devem interpretar-se como intrinsecamente atribuíveis a esses campos. Se incidem juntamente com fenômenos peculiares a estes, isso apenas testemunha a regência de áreas encefálicas de outras regiões em relação às frontais. Ora, segundo a análise anátomo-fisiológica a que temos procedido em outras ocasiões são particularmente as de situação parietotemporal que aí se refletem. Por outro lado, nos sintomas descritos é fácil reconhecer a participação de instintos pessoais e a da iniciativa, ao que dissemos de início. Temos pois aí uma série de fenômenos encadeados que assim poderíamos resumir, segundo a ordem de aparecimento após a injeção maciça de insulina: distúrbios vegetativos, neurovegetativos (11), transtornos vários de regulações vegetativas centrais, exaltação de instintos da personalidade, exacerbação da iniciativa sem coordenação adequada, perturbações intelectuais de gravidade crescente, até atingir o estado de coma.

Por outro lado Benedek focalizou os fenômenos propriamente subjetivos surgidos quer durante a fase pré-comatosa, quer ao despertar do coma (11). Nesse estudo, não menos notável, aparecem principalmente distúrbios perceptivos filiáveis a funções normais do córtex parieto-occipital: noção de movimento, percepção da continuidade de movimentos, percepções auditivas. Ora, tais noções, mesmo a de espaço objetivo, conquanto de âmbito sensorial, constituem na ação normal elementos primordiais que permitem a construção, con-

\footnotetext{
1 O. Magenau, segundo o trecho que encontramos citado por M. Müller (221, p. 160) admite igualmente a atuação da insulina mediante as regulações vegetativas centrais. Graças à amabilidade do dr. J. N. de Almeida Prado pudemos depois ler no orignal $o$ artigo referido (v. no 219 da Bibliografial.
} 
12 "Doença de Alzheimer sob a forma de apraxia construtiva alexia e agrafia. Considerações localizatórias e pato gênicas, a propósito de obser vação clínica pessoal.

13 Por gentileza de nosso prezado colega dr. J. N. de Almeida Prado pudemos ler o trabalho de A. Stief (224) publicado no Psychiatr. Neurol. Wochenschr. no de 22 de maio de 1937 Esse pesquisador externa a considerações a respeito desta possibilidade justamente. A coincidência de idéias e até mesmo de expressões é porém de tal ordem que nos sentimos obrigados a chamar a atenção para as datas, como tizemos anteriormente e a traduziraqui o trecho correspondente: "A esse respeito tenho como possique os processos químicos ulteriores desencadeados pela carência de oxigênio e a hiperemia reativa conseqüente à isquemia, a qual cria melho res condições de nutrição, também podem desempenhar um papel. Por ocasião de nossas pesquisas histológicas preocu pávamo-nos também com a extensão topística dos focos; comparando-os sob esse aspecto com a topografia dos territó rios maiormente (am meisten) a rados na esquizofrenia (Miskolczy, Hechst) chegamos de certa forma a encontrar as sim fundamento teórico para o prosseguimento daquelas pesquisas, se (insofern) é geralmente lícito partir dessas pesquisas em cães etirar conclusões quanto ao cérebro de esquizo frênicos. E provável que no processo esquizofrênico os gru pos celulares e territórios corticais que se encontram em disfunção e acarretam as peturbações psíquicas sejam - justamente em consequêencia da condição mórbida e caducidade (Hinfälligkeit) - excluídos mais facilmente e em primeira linha pelas desordens circulatórias: também não é imposs vel que certos territórios sejam ab ovo mais sensiveis - po motivos anatômicos locais ou outros - à carência de oxigênio" (224, p. 228 - grifos do originall. Esse trecho sublinhado da citação mostra entretanto que as conclusões finais de Stief são opostas às nossas. Ao passo que pensamos em estmulo localmente eletivo, apela ele para a destruição localmente efetiva. Prova-o ainda o se guinte passo: "Assim cheguei opinião de que tais terapêutcas de choque atuam em primeira linha mediante a exclusão transitória ou duradouradas células nervosas e desse modo poder-se-ia falar em uma inteessante e sutil exclusão cirúrgca, aliás incruenta, das células nervosas" lloc. cit. - grifos ain- forme teremos ocasião de evidenciar clinicamente (12). O aparecimento das desordens assinaladas por Benedek corresponde ao período que, na fase anterior ao coma, medeia entre as alterações de regulação vegetativa central e o desencadeamento dos fenômenos da atividade.

Essas duas ordens de fatos, os quais equivalem a verdadeira experimentação, certamente mais delicada que as de laboratório, induzem a crer que as funções intelectuais atingidas de preferência durante o coma insulínico são as que se ligam à perseverança e, secundariamente, à prudência, bem como indiretamente aos instintos que anteriormente referíramos. Analisemos esses fatos à luz das alterações anatômicas verificadas como sequiência do coma insulínico. São elas $(174,192,193)$ principalmente devidas à desnutrição das células em consequiência de espasmo vascular e se localizam, via de regra, no córtex cerebral. Temos como provável que, atingidas as funções vegetativas atribuídas aos núcleos cinzentos diencefálicos, o grave estímulo do choque visceral possa repercutir sobre o córtex de duas maneiras distintas: pela constrição vascular devida à ação direta dos núcleos vegetativos correspondentes, o que seria concomitante à repercussão sobre o instinto nutritivo; ou mediante esta repercussão, que iria excitar o destrutivo e depois influir sobre a coragem, cujo órgão preside a todas células motoras, inclusive do sistema simpático (Audiffrent) e iria dessa forma ocasionar espasmos vasculares, de onde a ação isquemiante. Julgamos possível entretanto que nos casos de atuação benéfica - isto é, naqueles em que as células isquemiadas se mostram capazes de reagir - a essa fase anêmica se sucede outra de hiperemia reativa, que portanto irá estimular o processo nutritivo e, de qualquer forma, excitar a vitalidade celular (13). Nos casos em que se praticou a verificação necroscópica só seria apreciável - ou porque desfavoráveis ou por simples casualidade - a fase de anemia e conseqüente perecimento celular. Tal suposição não a fazemos gratuitamente ou por mera fantasia: é, por um lado, admissível em razão de lei biológica fundamental e por outro digna de exame porque poderá explicar insucessos terapêuticos e concorrer para a seleção de casos adequados. Exprimamo-nos mais explicitamente: se a finalidade derradeira do choque insulínicoé a excitação biológica de certas áreas corticais, para produzir ele efeitos benéficos é preciso que tais áreas estejam - por força do distúrbio que se visa combater - em situação de deficiência funcional; na ocorrência oposta o tratamento viria agravar o transtorno referido. Porém, elas só conseguirão reagir biologicamente se as células nervosas respectivas estiverem íntegras ou pelo menos se as irreparavelmente lesadas forem em número relativamente pequeno.

Portanto a primeira condição de êxito é que os distúrbios não sejam do tipo "lesional", isto é, causados por desmantelo anatômico do cérebro em territórios fundamentalmente importantes. Depois, segundo nosso modo de analisar os sintomas esquizofrênicos, que o quadro clínico entre para a categoria que indicamos como de desordens primariamente afetivas; ou, quando provenham diretamente do declínio da atividade prática, que este seja causado por exaltação anormal da prudência, donde a deficiente produtividade.

Nosso modo de entender a dinâmica dos fenômenos mórbidos é ratificado não somente pela análise fisiopatológica do coma insulínico senão também pelas indicações que os casos clínicos da literatura fornecem. Estes não são, infelizmente, especificados de maneira explícita pelos autores, os quais - no intuito de registrar dados comparáveis - geralmente se limitam a indicar o tempo de doença com relação a cada grupo de remissão. De parte os psiquiatras que fazem menção explícita do tipo mórbido só é possível tirar conclusões a esse respeito nos poucos trabalhos que apresentam o quadro clínico dos pacientes. Assim, por exemplo, Dussik e Sakel (42) apenas se limitam a referir que os catatônicos agitados e os estuporosos reagem mal ao tratamento, exigindo modificações na técnica original do método; analisandose porém os casos clínicos assinala-se a 
predominância dos sintomas afetivos e dos de deficiência "secundária" de iniciativa entre os doentes remitidos, tanto nos $88 \%$ dos casos recentes como nos $58 \%$ dos que ultrapassavam meio ano de doença. Como na monografia de Sakel (169) também na comunicação verbal de Dussik (41) não encontramos especificação de formas clínicas. Os casos tratados já montavam entretanto a 220 dos quais $80 \%$ haviam retomado a capacidade para o trabalho e $70 \%$ denotavam completa a remissão. Ederle (46), na apreciação das remissões que obtivera com o choque insulínico em cotejo com as de doentes não medicados, apenas assinala o tempo de doença e o grau dos resultados, sem discriminar os subgrupos entre os $38 \%$ que chegaram à remissão completa, ou os $32 \%$ que haviam melhorado ou ainda os $30 \%$ que nada aproveitaram com o tratamento. Também Küppers (108) deixa de parte a subdivisão em tipos ao referir, no Congresso recente de Frankfurt am Main, os resultados francamente favoráveis que o método lhe proporcionava nos 23 pacientes que até então tratara e dos quais 10 se apresentavam curados ou em via de cura (14); mas o autor faz referência a pacientes agitados, justamente os que, embora em alguma coisa melhorados, não revelavam até a época da comunicação nenhum aproveitamento decisivo. Ignoramos a forma clínica dos pacientes estudados por Baranowski e colaboradores, os quais de resto chegam a conclusões pouco favoráveis ao método (10). Igualmente Feldhofen (48) se pronuncia pela pouca eficiência do processo de Sakel, cujos riscos e cujas dificuldades técnicas não the compensariam o emprego. Ainda entre os que não apreciam o método se encontra Langfeldt, que praticara na Clínica de Pötzl e que rotula como de tipo “exógeno" muitos dos pacientes de Sakel; tratou porém somente 8 doentes, cuja variedade clínica especifica: 3 deles não suportaram bem o tratamento, que foi interrompido; em 1 demente paranóide o resultado foi nulo; 3 catatônicos de tipo "processual" apresentaram melhoras quanto aos sintomas acessórios; finalmente houve boa remissão num esquizofrênico do grupo hebefrênico-paranóide (112 - grifo nosso); notar que, malgrado o pequeno número de casos, a verificação de Langfeldt confirma o nosso conceito sobre a escolha dos casos (15).

Uma vez porém que os psiquiatras levem também em consideração esse fator importantíssimo que consiste na diferente suscetibilidade dos vários tipos clínicos à ação do choque insulínico, a separação prévia dos casos adequados será relativamente fácil; e pelos dados que até agora conhecemos estamos autorizados a esperar que o progredir da experiência venha confirmar o nosso modo de considerar essa palpitante questão.

Passemos ao tratamento pelo método convulsivante.

Também aqui deixamos de parte a técnica propriamente dita que por ora não nos interessa diretamente e ademais será objeto de outra comunicação. Somente importa referir que, conforme à modalidade definitiva $(134,136)$, consiste em provocar convulsões epileptiformes mediante injeções endovenosas rápidas, repetidas segundo a série crescente, do medicamento caridazol - sempre em dose “supraterapêutica”. Orientara Von Meduna as próprias investigações nessa rota efetivamente nova e fértil inspirado num trabalho "não sobre esquizofrenia" porém, relativo "ao cabedal de epiléticos" do Instituto em que trabalha. “O autor", escreve Von Meduna, "verificou que os epiléticos de nosso estabelecimento haviam sarado na proporção de $1,05 \%$; porém quando à epilepsia se associava a esquizofrenia saravam $16,05 \%$. Essa diferença de 16 vezes é tão considerável que não pode ser atribuída ao acaso, dado o número relativamente grande dos pacientes ( 176 casos), senão antes me fez pensar em antagonismo biológico de certa forma especial que parece existir entre ambas as doenças" (136, p. 6).

A pesquisa feita então deliberadamente na literatura psiquiátrica reforçou-lhe o modo de pensar, que assim consubstancia: "Entre a epilepsia e a esquizofrenia existe um antagonismo biológico. Quando se consegue provocar um ataque epilético em paciente esquizofrênico, esse ataque altera da do original). Acentuemos que as deduções práticas ase refirar de ambas as concepcões seriam também oposta: segundo a orientação de Stie os esquizofrênicos lesionais e principalmente esses - aproveitariam o tratamento; nós a contrário julgamos que nesses casos precisamente, mesmo quando recentes, há pouca probabilidade de êxito

14 Em 1937 o total de pacientes era de 36 , dos quais o número de curados e de melhorados atingia respectivamente 8 e 15 ver no 217 da Bibliogratia

5 Também Von Angyale Gyárfás referem em artigo cujo resumo lemos no Zbl. f. d. ges. Neur. u. Psychiatrie - no de maio de 1937 - que os casos pessoais estuporosos não aproveitaram o tratamento, ao contrário do que se deu com os 5 pacientes do tipo catatônico ou poranóide (213). 
o meio interno - químico, humoral, hematológico - de tal forma que é por isso que o meio assim modificado representa um terreno desfavorável para o desenvolvimento da esquizofrenia, se cria uma possibilidade biológica de fazer regredir a doença (loc. cit., p. 7)".

Os dados objetivos nos quais tal hipótese se fundamenta representam fatos reais: basta apreciar os resultados práticos indiscutivelmente alcançados desde que Von Meduna conseguiu encontrar o meio eficiente de produzir com segurança convulsões epileptiformes no homem. Porém a noção de antagonismo entre epilepsia e esquizofrenia não concorda totalmente com os fatos objetivos conhecidos clinicamente nem constitui - segundo nosso modo de considerar o problema - elemento necessário para explicar os resultados. Assim, por exemplo, se A. Glaus (60) admite essa oposição baseando-se no estudo de grande massa de epiléticos, se por outro lado G. Müller (145) descreve o caso de 2 esquizofrênicos que entraram em remissão após apresentarem convulsões epiléticas espontâneas (10), não é menos certo que outros fatos objetivos também irrecusáveis conduzem a conceito contrário ou pelo menos diverso. Mediante a excitação elétrica produzida em cérebros de cães, coelhos e gatos, por via transcraniana, no intuito de contraprovar os distúrbios da série catatônica (67), pôde Gullotta verificar que as convulsões provocadas não interrompiam os sinais cataleptiformes; e experimentara também em animais tratados previamente pela bulbocapnina. Experiências relatadas ulteriormente (68) ainda lhe permitem negar a eficiência das convulsões a esse respeito. Igualmente Vitello não encontra antagonismo entre ambas as variedades mórbidas (201), o que aliás também deduzimos, de certa forma, do interessante estudo publicado por Volland (204). Parece-nos pois que o problema pode ser posto em outros termos; a doutrina que seguimos, relativa às funções cerebrais (181), autoriza-nos a analisar tais fatos de modo menos complexo, como adiante diremos.

Em sua obra portentosa (9), depois de descrever magistralmente os fenômenos catalépticos diz G. Audiffrent: “A faculdade que possui o corpo do cataléptico de deixar-se de certa forma plasmar como cera mole seria a consequiência de dois fatos: por um lado, abolição da sensação muscular, por outro, contração muscular permanente devida à disposição anormal do órgão que mantém os movimentos" (p. 570) Em outro ponto onde aprecia fenômenos correlatos - perda de consciência, amnésia - entre catalepsia e epilepsia. “A abolição da vontade na catalepsia, tanto como na epilepsia, nos obriga pois a admitir que nos dois casos os órgãos da atividade estão desviados de toda operação mental; mas as convulsões da epilepsia e as contrações musculares permanentes, próprias à catalepsia, nos indicam também de um lado e de outro que a região da atividade se acha inteiramente absorvida pelo estímulo que exerce sobre o sistema muscular [...] Se na epilepsia o órgão da coragem se encontra numa disposição anormal, conseqüiência de viva vibração desse órgão, a permanência da contração na catalepsia, a coincidir com a perda de memória e com a abolição da vontade, bastaria já, em rigor, para fazer supor que nesta doença o órgão da firmeza está por sua vez em situação análoga" (p. 568). E ainda noutro passo: "Esta paralisia (a da região encefálica preposta às funções de atividade), como ressaltará melhor no decorrer da presente exposição, é a conseqüência de uma exaltação espontânea da região ativa e da ação enérgica que sobre esta exerce um órgão afetivo fortemente excitado. É o que ocorre, por exemplo, em certos acessos de epilepsia espontânea ou nos acessos de cólera violenta" (p. 519).

Estas correlações entre atributos subjetivos se apreciam, quanto ao aspecto estritamente anatômico, pelas conexões neuronais e, além disso, pela possibilidade de repercussão fisiológica entre áreas corticais relativamente distantes (182). No caso da epilepsia ou, mais genericamente, das convulsões epileptiformes, o estudo anátomo-clínico bem conduzido pode distinguir as lesões primitivas das que ao contrário são resultantes, como se vê dos estu- 
dos de Scholz (176), de Spielmeyer (185187); como também é exequiível em grande percentagem dos casos verificar as vias principalmente comprometidas - tal o que fizeram Filimonoff (50, 51), Grünbaum (66), Pike e colaboradores (154) - ou pelos caracteres localizatórios identificar os campos arquitetônicos de onde provêm as excitações convulsivantes. Para conclusões neste último setor assumem valor por vezes inestimável não só os fenômenos propriamente neurológicos, consoante o demonstram os trabalhos de Bucy (29), de Foerster $(53,54)$, de Trendelenburg (200), porém mesmo os que se consideram de ordem psíquica, tal o que ressalta, para exemplificar, do trabalho de Steblow (189).

As convulsões epileptiformes, conquanto fenômeno de ordem essencialmente motora, podem provir de excitações originadas em áreas cerebrais distantes da zona propriamente afeta à motilidade. Foerster pôde demonstrar tal fato não apenas clinicamente, pela excitação elétrica no homem, mas ainda mediante a verificação cirúrgica $(53,54)$; é dele o esquema que abaixo reproduzimos (Fig. 2). A função subjetiva dessas áreas, entretanto, somente pode apreciar-se pelo estudo dos fenômenos intercomiciais no caso dos epiléticos ou pelo exame clínico aprofundado dos pacientes com lesão cerebral em foco.

Com referência aos distúrbios tônicoclônicos desencadeados durante o choque convulsivante inaugurado por Von Meduna não é, infelizmente, fácil a análise fisiopatológica aprofundada como a fizeram respectivamente Von Angyal e Benedek, nos trabalhos já citados $(7,11)$. É que os acessos decorrem rapidamente - em média entre 30 segundos e pouco mais de 1 minuto - desencadeando-se em geral imediatamente após a injeção, às vezes decorridos alguns segundos. Não obstante, pequenas variantes individuais podem ocorrer durante as diversas fases do paroxismo, bem como no comportamento das próprias convulsões ante a série convulsivante. Tais particularidades, já bem referidas por Von Meduna, adquirem a nosso ver significado semiológico, mormente quando confrontadas com os fenômenos localizatórios porventura arroláveis na sintomatologia do doente (17). Aliás o próprio decurso dos paroxismos provocados, como tipo médio abstrato, fornece indicações sobre o modo de ação do medicamento, no caso o cardiazol.

Quando a dose injetada se mostra eficiente os fenômenos desejados se iniciam, como ficou dito, ao terminar-se a injeção ou durante os primeiros segundos que a ela se seguem. Sobrevêm - ao mesmo tempo que os distúrbios vasomotores no rosto alguns movimentos clônicos das pálpebras, tosse seca e breve, no mesmo instante em que se obnubilam os processos intelectuais; sobrevém a fase tônica, generalizada, acompanhada de espasmos de mandíbula e por vezes de pequenos movimentos extrapiramidais nas extremidades, o que já se processa em pleno estado de inconsciência; dentro de alguns segundos ainda irrompem os movimentos clônicos, algumas vezes com início “localizatório”, acompanhados não raro dos distúrbios concomitantes comuns no acidente comicial clássico. Segue-se-lhe sono profundo, comatoso, por poucos minutos. Variações individuais - o tipo dos fenômenos vasomotores, a duração da fase tônica em relação à clônica, peculiaridades desta última, finalmente o tipo da amnésia subseqüente ao ataque, o comportamento ulterior dos processos intelectuais, mesmo a eventualidade e o tipo dos "equivalentes psíquicos" - constituirão indicações por vezes preciosas. Um fato geral é porém digno de nota e foi já registrado pelo autor do processo: o período clônico é sempre múltiplo do tônico e geralmente cresce progressivamente no decorrer da série, muitas vezes ao inverso daquilo que se dá com este último.

Essas diversas peculiaridades induzem a pensar que o cardiazol em doses "supraterapêuticas" atua mediante a intoxicação direta do encéfalo, como admitem alguns autores em relação também a outros meios convulsivantes. Não cremos que os paroxismos se devam à ação tóxica propriamente dita - que nesse caso seria brutal - primeiro porque Von Meduna demonstrou $(133,136)$ experimentalmente não ocorrer
17 Este particular constitui objeto de duas comunicações da pre sente série, já inscritas para apresentação ante a Associa cão Paulista de Medicina: II - "Modalidades do ataque provocado; importância semiológica e prognóstica. Análise das observações pes soais à luz da patologia cere bral"

III - "Distúrbios de percepção e de expressão desencadeo dos pelo choque convulsivante. Ensaio clínico localizatório baseado nas observações pessoais" 


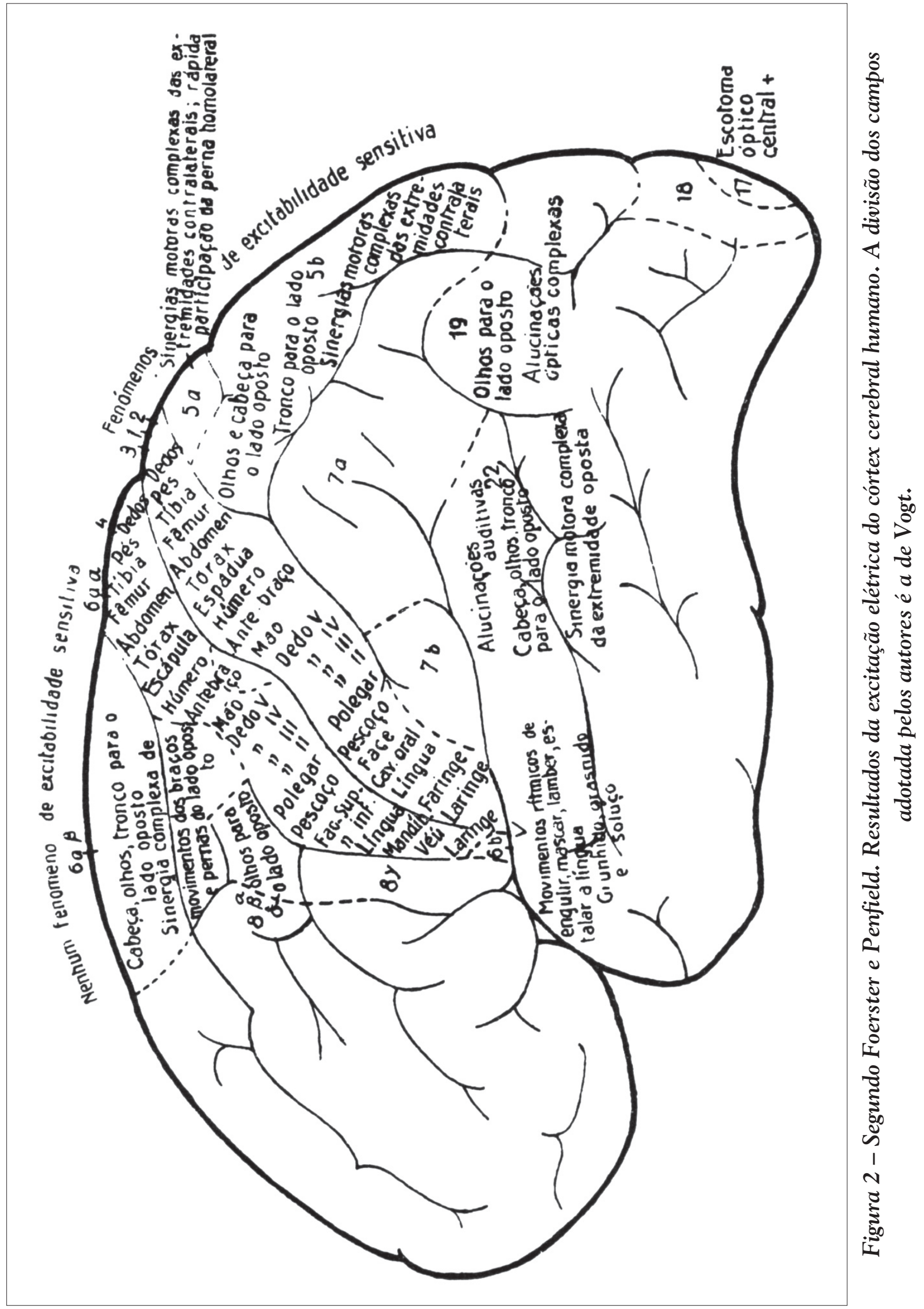


com a nova terapêutica, mesmo em dose letal para o animal em experiência, lesão perivascular no sistema nervoso (18). Ademais a larga aplicação clínica já divulgada quer com finalidade terapêutica, quer, como fizeram Tancredi e Pinto de Toledo (194), para o diagnóstico de epilepsia, não autoriza a concluir pelo choque tóxico no sentido próprio. Cremos porém, com apoio nos fatos clínicos já relatados, que a ação se desenvolva primitivamente no córtex encefálico (19), pois os distúrbios de origem cortical sobrevêm incontinenti ou pelo menos sem a precedência de fenômenos vegetativos periféricos e depois diencefálicos como ocorre no coma insulínico. Dada a dificuldade de análise fisiopatológica - devido à brevidade dos fenômenos paroxísticos - não se poderiam desde já identificar as zonas corticais correspondentes; todavia não julgamos tarefa impossível uma vez que se empreendam pesquisas sistemáticas. Experimentando sistematicamente o meio convulsivante em animais submetidos antes à destruição laminar de Dusser de Barenne $(39,40)$, ou recorrendo a técnica assimilável à de Kornmüller (97), ou ainda escolhendo para estudo do choque convulsivante epiléticos com lesões orgânicas analogamente ao que no domínio da excitabilidade elétrica fizeram Foerster e Penfield (54), poder-se-ia inferir alguma conclusão. É que as convulsões provocadas ocorrem dificilmente em indivíduos com lesão orgânica cerebral e isso permitiria utilizar assim de vários modos o método das exclusões. Essa atuação eletiva seria possivelmente orientada pelo comportamento diverso das distintas áreas corticais ante a composição química do produto introduzido em dose maciça no meio interno.

Semelhante hipótese não discrepa de forma alguma dos conhecimentos que já se acumulam abundantemente em relação ao comportamento biológico dos órgãos encefálicos: as diversas porções do sistema nervoso central denotam propriedades distintas que de certa forma os diferenciam como órgãos, e dentro do próprio córtex encefálico se verifica, de modo por vezes nítido, a individualização de áreas distintas e às vezes contíguas. Assim, se a atividade psíquica exige que todo o encéfalo se encontre solidariamente em ação, não é menos certo que cada órgão encefálico concorre de maneira diversa para o conjunto das funções. Semelhante atividade psíquica aferível até há pouco apenas pelo exame funcional, isto é, psíquico, pôde ser evidenciada quanto aos fenômenos físicos a ela correlatos, graças aos estudos notáveis de A. E. Kornmüller. Aperfeiçoando no decorrer de decênios as tentativas anteriores, de escasso interesse prático, chegou esse pesquisador do Kaiser-Wilhelm Institut für Hirnforschung, Berlin-Buch, não só a registrar os fenômenos elétricos ligados à atividade do córtex cerebral (94), mas ainda a demonstrar que tais fenômenos variam conforme o campo arquitetônico do qual provêm (91-95,98-100); este distintivo fundamental - superponível às diversidades estruturais do córtex - pôde ser apreendido também no estado anormal quer provocado pela ação local de drogas sobre o córtex (97), quer em condições patológicas diversas (96). Graças à colaboração especializada de J. F. Tönnies (100, $198,199)$ e aos estudos aprofundados de $\mathrm{H}$. Berger, quer no estado normal (12-16, 18), quer sob condições mórbidas como no acesso epilético (17), esse gênero de investigações sobre a atividade fina, psíquica, correspondente aos diversos campos da substância cinzenta cortical pôde entrar para o rol das conquistas fecundas. Numerosos autores o têm demonstrado $(1,35,38,62$, $70,71,122,123,183)$, examinando os "fenômenos bioelétricos", sob as mais variadas condições fisiológicas do cérebro, seja perante o estímulo sensorial, seja durante o sono normal, a narcose, ou mediante a ação de tóxicos, ou ainda durante convulsões epileptiformes.

Porém não são somente as diferenças de comportamento verificáveis ante o “eletroencefalograma” o que autoriza nossa hipótese. Duas outras ordens de estudos também a justificam e mais diretamente: não só as diversas zonas do cérebro se denotam distintas pelas reações químicas delicadas e pelo chamado "metabolismoin-
18 A. Stief, no trabalho recente já citado (224), atribui as convulsões também aqui a espasmos vasculares e apela para duração dos paroxismos como causa da maior ou menor acentuação das lesões anatômicas cerebrais.

19 Fr. Duensing estampa no Münch. Med. Wschr 84 nde 25 de junho de 1937, um artigo em que procura nega valor diagnóstico à prova; in eressa-nos aí o fato de também admitir, baseado na observação direta a ação cortical do cardiazol /p. 1.015) (v. no 214 da Biblio grafia). 
termediário" como ainda existem drogas que agem de modo eletivo sobre o córtex ou sobre o tronco encefálico. Demonstramno por exemplo as pesquisas de Gorodisskaja e Drobowa (61) relativas à colesterina, aos cerebrosídios, aos fosfatídios e ao azoto total na zona motora e nos centros associativos, de ambos os hemisférios; as de Landa-Class e Maiman que, como os autores precedentes, afirmam a possibilidade do que chamam "topografia química do cérebro" (109); as de Riebeling (161), o qual investiga o amoníaco, o azoto protéico, o cálcio e o cloro em vários setores do cérebro normal e também sob condições mórbidas; as de Rose (163), que conclui pela especificidade topográfica de reações microquímicas, evidenciando ainda a maior ou menor resistência de certas regiões e mesmo de certas camadas corticais ao estudá-las mediante a reação da oxidase; as de Schwartz e Cohn, também orientados segundo a concepção diretriz de Vogt e igualmente concludentes quanto à topografia patológica evidenciável quimicamente (177); ainda as de Tschalissoff (195), o qual também investiga com colaboradores o "metabolismo cerebral intermediário" em esquizofrênicos (196); finalmente as de Wosskressenski (209), igualmente procedidas em doentes mentais. O mesmo diremos quanto aos trabalhos que focalizam a ação de drogas sobre o sistema nervoso e a presença eletiva delas em várias regiões $(33,83-85,116$, 203, 212) ou então os que demonstram a ação antagônica de medicamentos no córtex e no tronco encefálico $(121,137,142,207)$. Com referência particular aos estímulos no domínio dos núcleos vegetativos diencefálicos - e que segundo dissemos constitui tempo importante na atuação do coma insulínico - temos apoio em trabalhos memoráveis como os de G. Bodechtel (22), R. Grewing (63) e Josephy (82) pelo aspecto anatômico; bem como, pelo lado fisiológico e em parte experimental nos de C. Ceni (31 e principalmente 32), C. Von Economo (44, 45 e em parte 43), W. R. Hess (77), M. Sakel (168-170), de H. Weese (207); e ainda em outros de ordem experimental ou anátomo-patológicos, como os dos autores que enumeramos: G. Agostini (2), L. Von Bogaert (23), V. Demole (34), K. Kisimoto (86), E. Leschke (118), J. Lhermitte (119, 120), J. Lhermitte e A. Tournay (121), A. C. Pacheco e Silva (150), St. N. Rowe (167), S. A. Sarkissow (172). H. Scharfettere Th. Seeger (173), K. Stern (191), A. E. Walker (206), Fr. Wichert (208), H. Zweig (212). Finalmente adquire para nós importância capital o fato demonstrado experimentalmente por F.-W. Kroll: produzia artificialmente, mediante a excitação cortical farádica, convulsões em cães e coelhos; depois, com o extrato cerebral do córtexmesmo de outras zonas que não a motora - desses animais, produzia em outros também convulsões, apenas pela introdução direta nos espaços aracnoidianos (102, 103); unicamente o extrato cerebral - e não o da região peduncular nem o do eixo raquidiano - era eficiente; experiências análogas lhe permitiram transmitir a gatos normais o sono mediante o transporte de substâncias extraídas de outros exemplares adormecidos experimentalmente (104). Vale dizer que a atividade das diferentes zonas cerebrais, no caso das convulsões por exemplo, está em estreita correlação com o metabolismo celular e mesmo com estímulos químicos, naturalmente secundários.

As hipóteses que vimos desenvolvendo ressaltam dos dados clínicos, por certo analisados segundo as concepções que seguimos no que entende com a patologia cerebral, mormente sob o aspecto localizatório. Mas por sua vez tais concepções se acham, conforme temos dito em outras ocasiões, plenamente de acordo com os conhecimentos contemporâneos. Sob esse aspecto particular poderíamos frisar, no domínio da esquizofrenia, os trabalhos de $\mathrm{N}$. Bruchanski (28), G. Bychowski (30), V. Dimitri e M. Victoria (36), J. Frostig (56), E. Fünfgeld $(57,58)$, B. Hechst (72-74), D. Miscolczy (140, 141), I. Somogyi e L. Von Angyal (184); os de A. Von Braumühl (27), I. N. Filimonoff $(50,51)$, O. Foerster e W. Penfield (54), A. A. Grünbaum (66), G. Hermann e E. Wodach (76), R. Orlando 
(149), J. Pereyra Käfer (152), F. H. Pike e outros (154), C. Schneider (175), Ph. Schwartz e R. Cohn (177), dentre os que confrontam as lesões anatômicas encefálicas, principalmente as focais, com os distúrbios resultantes; e ainda, quanto à maneira de filiar os sintomas em geral à estrutura anatômica, os estudos de C. Ceni (31), B. Fernandes (49), K. Kleist (88-90), A. E. Kornmüller (98, 99), J. Lange (110), F. Morel (143), W. Poppelreuter (156) e finalmente O. Pötzl (157).

Assim, reportando-nos ao que dissemos linhas atrás, a zona cortical correspondente ao órgão da iniciativa, o qual como vimos preside diretamente à motilidade, constituirá o ponto onde vão atuar as excitações do cardiazol, seja diretamente, seja pela confluência do estímulo produzido em outras áreas do córtex. E isso não só pelo fato de sobrevirem de modo primário as convulsões provocadas, mas ainda por essa particularidade de, à medida que as sessões terapêuticas se repetem, ir-se exaltando a excitabilidade da zona motora, o que se traduz pelo predomínio da fase clônica sobre a tônica. Ademais, a maior ou menor excitabilidade do órgão referido guarda paralelo com a probabilidade de êxito. Ora, o raciocínio que externamos a propósito do coma insulínico vale também aqui para com o efeito do agente convulsivante: o resultado final só será favorável se a região onde atua esse agente se encontrar em deficiência funcional. E como o órgão da coragem - na acepção que adotamos - impele à atividade intelectual por um lado, por outro recebe o influxo de certos territórios destinados à afetividade, nos quais por sua vez influi diretamente, será necessário analisar detidamente o quadro esquizofrênico a fim de que a indicação para a terapêutica seja estritamente formulada. Essa correlação dinâmica relativamente complexa constitui indubitavelmente, na nossa opinião, os fatores desconhecidos a que se refere Von Meduna quando estuda o mecanismo de ação do próprio método (136): “Em relação à tendência para a remissão (Remissionsbereitschaft) devemos contar com fatores extraordinariamente numero- sos-em parte inteiramente desconhecidos - de modo que é atualmente impossível estabelecer uma dependência bem definida entre a dose convulsivante e a intensidade do processo, bem como do decurso (Erscheinungsformen) do tratamento" (p. 16). "A tendência dos pacientes para a convulsão é influenciada principalmente por fatores ignorados" (p. 115). É que - além das correlações de outras áreas -é necessário contar com a possibilidade de haver lesões já anatômicas nas zonas corticais que, segundo o que temos mencionado, desempenham funções regidas pela qualidade prática de iniciativa.

Chegamos assim ao tipo clínico adequado para o tratamento convulsivante. Segundo a observação de Von Meduna a respeito dos seus 110 pacientes, os resultados melhores foram os que verificou nos hebefrênicos (remissão de 6 entre 9 doentes), depois nos esquizofrênicos paranóides (18 remissões em 33 desse grupo), depois os de tipo simples (23 remissões num total de 45); dentre os catatônicos - num total de 23 - apenas 7 obtiveram remissão. Ora, cumpre notar que no grupo catatônico se incluem pacientes com fenômenos hipercinéticos, o que vale dizer, cujas desordens predominantes não advêm diretamente da deficiência de iniciativa, porém sim do predomínio da prudência e dos impulsos afetivos a ela mormente ligados.

Segundo a apreciação em abstrato que anteriormente procuramos resumir, seriam mais passíveis de tratamento mediante convulsões os esquizofrênicos com embotamento simples da iniciativa, com desinteresse pelo ambiente e, ao menos em aparência, pela própria situação, com predominante carência de expressão, de forma habitual; finalmente aqueles em que os distúrbios afetivos transparecem principalmente no embotamento, na agressividade e ainda no negativismo (20). Para o completo resultado do tratamento não basta porém selecionar o tipo clínico; faz-se necessário que as desordens não resultem de lesão irremediável da zona cortical primariamente atingida no processo mórbido, ou naquelas em que este repercute. Apenas a deficiên-
200 já várias vezes referido artigo de M. Müller (221) no Fortschritte der Neur. und Psychiatrie, vol. 9 , no de abri de 1937, traz a esse respeito conclusões pessoais que cor roboram de maneira integral o nosso modo de ver. São palavras daquele autor: "Lembro que vários autores se referem a resultados menos favoráveis, e a dificuldades particulares de tratamento mediante a insulinoterapia, nos casos de estupo ao passo que por outro lado todos os pesquisadores têm confirmado a tendência das ormas paranóides precisamente para esse método. Talvez cheguemos dessa forma a diferenciar algum dia os casos segundo a particular indicação para a insulina ou para o cardiazol; e possivelmente de orma que se indiquem para insulina as formas paranóide e catatônico-alucinatórias, tavez as catatonias agitadas, ao contrário para o cardiazo os casos estuporosos e principalmente aqueles em que aparecem no primeiro plano negativismo e o bloqueio Sperrung)" (p. 165). Essa confirmação com ser para nós sobremaneira honrosa obriga-nos ainda uma vez a comprovar que as consideracões que acima expendemos já constituíam o ponto de par tida para os estudos que desde o ano passado vínhamos empreendendo. Editado em abril, o no respectivo do Fortschritte só nos poderia che gar às mãos depois que o presente trabalho se achava completo para a exposição na Associação Paulista de Medicina e já munido do visto da Diretoria Geral do serviço a que pertencemos. Todavia, como a apresentação só se verificou a 5 de julho passa do, devemos exibir prova me nos duvidosa de nossas asserções. Por isso para aqu transcrevemos as cartas que a esse respeito em marco e em maio, dirigíramos a Von Meduna. Da primeira em data 3 de março de 1937| traduz: mos os seguintes tópicos: "T nho acompanhado vossas pu blicações a respeito desse tra tamento cuios resultados rea mente notáveis exigem que seja aplicado largamente. Venho me preocupando de longa data comoé natural, comesse grave problema psiquiátrico que é a esquizofrenia; e os vossos trabalhos vieram confirmar por forma brilhante e ine perada as concepções patogènicas segundo as quais encaro as formas mórbidas em psiquiatria. No caso particular da terapêutica convulsivante acredito que poderão contribui para ela de alguma forma os estudos que estou efetuando 
neste hospital, alguns em colaboração com colegas daqui. Seria para mim muito útil, para estabelecer todos os fatores co pazes de diminuir o sucesso do tratamento, se pudesse juntar à minhas observações pessoais d casos catatônicos desfavoráveis as que foram registradas na vos a divisão hospitalar: pedir-vo a então, caso não vos foss difícil ou importuno, uma cópia da história clínica abreviada da súmula dos dados psiquiátricos principais da observação hospitalar, correspondentes aos 16 casos não remitidos de esquizofrenia catatônica, referidos no vosso livro sobre Konvulsionstherapie de Schizophrenie". Etc. Responde nos Von Meduna a 10 de abril solicitando maiores esclarecimentos. De nossa segunda car a - com a data de 10 de maio - extraímos o seguinte trecho: "Em relação a vosso pedido de maiores esclarecimentos devo dizer-vos que desejo obter os resumos das histórias clínicas referentes aos 'casos de catatonia não remitidos'. Meu fim, principalmente, é verificar m cada caso de catatonia que não aproveitou o tratament convulsivante, se predominam tipo hipercinético ou mesmo agitação, ou se ao contrário a hipocinésia e os fenômenos neurológicos cataleptiformes igados à 'carência de iniciativa' (Kleist). Basta para cada caso um resumo semelhante ao dos doentes que entraram em remissão /como por exemplo os casos 2, 6, 7 de vosso livro) ou então mesmo, o que talvez vos seja mais fácil, apenas os dados: "Caso no ...; idade. ... história clínica resumida e duração da doença antes do tralamento; forma predominante (agitada, perplexa, embotada); predominância ou treqüência maior de fases de embotamento ou de agitação, hipercinésia exciłação psíquica; ou então decatatonia estupor carência de iniciativa, perplexidade" Etc. Esses dados evidenciam bem o nosso modo de pensar servem para testemunhar que na realidade antes das publ cações a que aludimos a nossa atenção já se voltava para fato de que no grupo da catatonia cumpre distinguir os doentes que - de acordo com a doutrina que seguimos em relação às funções cerebrais são propícios ao tratamento convulsivante e aqueles em que não é de esperar-se proveito com tal método. cia funcional, quer das áreas intelectuais, quer das que regem a atividade, poderia ser reparada pelo estímulo diretamente dirigido sobre o órgão afeto à motilidade. Esse mesmo fato de as lesões anatômicas representarem o empecilho irremovível para a reeducação funcional é o que a nosso ver explica que o cardiazol possa produzir resultado ainda em época mais tardia. Porque os transtornos anatômicos cerebrais devidos à inatividade funcional sobrevêm mais tardiamente quando aos órgãos correspondentes falta apenas o estímulo da iniciativa do que quando este resulta de distúrbio na esfera afetiva e principalmente quanto ao instinto da nutrição, o qual preside aos próprios fenômenos do metabolismo celular.

A análise organológica segundo a qual nos orientamos permite-nos, assim, dispensar a hipótese de antagonismo humoral entre esquizofrenia e epilepsia para explicar os resultados do tratamento convulsivante. Permite-nos, por outro lado, tentar explicar a diversidade de ação entre o choque convulsivante de Von Meduna e o coma provocado pelo método de Sakel. Segundo o que do exposto inferimos a insulina age primariamente sobre o instinto de conservação pessoal mediante o choque visceral; o cardiazol, ao contrário, atua primariamente sobre a atividade prática, excitando de modo direto a zona correspondente no córtex cerebral.

Esse nosso modo de encarar a questão permite ademais retirar conclusões de ordem prática em assunto cuja importância não é mister encarecer. E entendem elas com a discriminação dos quadros clínicos adequados para cada um desses processos terapêuticos:

1) O tratamento de Von Meduna encontra indicação particular: a) nos esquizofrênicos de tipo paranóide predominante; b) nos de tipo catatônico em que predomina a carência de iniciativa; c) nos de tipo acentuadamente hebefrênico.

2) O choque insulínico deve ser aplicado especialmente: a) nos esquizofrênicos em que predominam desordens de afetividade, no sentido que acima referimos; b) nos de tipo paranóide em que predominam os sintomas hipercinéticos, a incoordenação motora, a instabilidade intelectual; c) nos casos que de início denotam tendência grave para a forma demencial.

3) Se os transtornos não são de data recente ou se o ambiente hospitalar não permite a atuação moral eficiente após a fase de coma, será preferível recorrer ao tratamento de Von Meduna em primeiro lugar.

4º) O tempo de doença deve ser levado em consideração, para efeito de prognóstico, apenas como possibilidade de que as alterações cerebrais já tenham tomado o caráter de irremovíveis.

Tais considerações, baseadas no estudo minucioso dos casos clínicos que até hoje nos têm passado pelas mãos e na análise dos fatos registrados na literatura psiquiátrica, carecem ainda da verificação explícita em larga escala. Por isso, e porque elas nos orientam nos estudos que estamos efetuando, julgamos preferível expendê-las ao iniciar o relato dos nossos trabalhos, a fim de que a crítica dos ilustrados colegas nos auxilie a corrigi-las de acordo com os dados objetivos.

\section{BIBLIOGRAFIA}

1 ADRIAN, E. D.; NAMAGIVA, K. The Origin of the Berger Rhythm - Brain, 58, pp. 323-531, 1935.

2 AGOSTINI, G. "Sulle alterazioni della citotettonica della corteccia cerebrale nell'encefalite epidemica cronica.

(Studio comparativo tra i due emisferi)", in Ann. Osp. Psichiatr., Perugia, 29, pp. 153-66, 1935

(Zentralbl. f. d. ges. Neurol. u. Psychiatrie, 82, p. 551, 1936).

3 ALMEIDA, M. Ozorio de. "Observations sur l'excitation mécanique ou électrique de l'écorce cérébrale à travers la peau", in Rev. Soc. argent. de Biologia, 10, no suppl., pp. 420-8, 1934. 
4 AlmeldA PRAD0, J. N. “Do Pneumoencefalodiagnóstico em Psiquiatria”, in Gazeta Clinica, São Paulo, 35, pp. 29-39, 1937.

5 ANGYAL, L. Von. "Beiträge zur periodischen Schizophrenie und den schizophrenen Dämmerzuständen”, in Allg. Zeitschr. f. Psychiatrie, 102, pp. 185-216, 1934. . "Gemeinsames Vorkommen Von unterparietaler Symptomengruppe und anatomischen Lageveränderungen bei einem Fall Von Schizophrenie", in Orv. Hetil. (Ungar), pp. 555-7, 1936 (Zentralbl. f. d. ges. Neurol. u. Psychiatrie, 82, p. 376, 1936). "Über die motorischen u. tonischen Erscheinungen des Insulinschocks. Beiträge zur Physiologie

u. Pathologie des men schlichen Stirnhirns bei der Insulinschockbehandlung Schizophre ner", in Zeitschr.f. d. ges. Neurol. u. Psychiatrie, 157, pp. 35-80, 1937.

8 ANGYAL, L. Von; M. SAKEL. "Insulinbehandlung des Pubertätsirreseins", in Orv. Hetil. (Ungar.), 1936, pp. 35961, 386-9 (Zentralbl. f. ges. Neurol. u. Psychiatrie, 82, p. 353, 1936).

9 AUDIFFRENT, G. "Maladies du, cerveau et de Virmervation", 1 vol., XIV, 528p., Paris, Dunod, 1869.

10 BARANOWSKI, L.; BORISOWICZ, J.; MARZYNSKI, M.; OSSENDOWSKI, A.; PARADOWSKI, J.; WITEK, St.

"Methode der Insulinbehandlung der Schizophrenie", in Roczn. psichiatr. (Pol.), 25, pp. 161-77, 1935

(Zentralbl. f. d. ges. Neurol. u. Psychiatrie, 80, p. 352, 1936).

11 BENEDEK, L. Insulinschockwirkung auf die Wahrnehmung. Wien (Karger), 1935.

12 BERGER, H. “Über das Elektrencephalogramm des Menschen”, in Journ. f. Psychol. u. Neurol., 40, pp. 160-79, 1930.

13

14 . "Das Elektrencephalogramm des Menschen", in Münch. medizin. Wochenschr., 1932, II, pp. 1636-8. . "Über die Tätigkeit des menschlichen Grosshirns", in Münch. medizin. Wochenschr., 1933, I, pp. 844-6.

15

16 . "Das Elektrencephalogramm des Menschen", in Med. Welt, 1933, pp. 928-9.

. "Die physiologischen Bedingungen der Bewusstseinserscheinungen", in Zeitschr. f. Psychologie, 132, pp. 360-70, 1934, e Psychiatr.-neurol. Wochenschr., 1935, pp. 65-7 (Zentralbl. f. d. ges. Neurol. u. Psychiatrie, 74, p. 437, 1935 e 77, p. 309, 1935). "Über die Entstehung der Erscheinungen des grossen epileptisch. Anfalls.", in Klin. Wochenschr., 1935, 1, p. 217-9 (Zentralhi. f. d. ges. Neurol. u. Psychiatrie, 76, p. 190, 1935). ."Das Elektrencephalogramm des Menschen.", in Naturwissenschaften 1935, 121-124

(Zentralbl. f. d ges. Neurol. u. Psychiatrie, 77, 130, 1935).

19 BERZE, J. "Störungen des psychischen Antriebes", in Zentralbl. f. d. ges. Neurol. u. Psychiatrie, 142, 730-773, 1932.

20 BICKEL, 0. "Les symptômes neuro-végétatifs dans les maladies du système nerveux central”, in Schw. Arch.f. Neurol. u. Psychiatrie, 33, 192-218, e 34, 1-11, 1934.

21 BLEULER, E. "Primäre und sekundäre Symptome der Schizophrenie", in Zeitschr. f. d. ges. Neurol. u. Psychiatrie, 124, 607-646, 1930.

22 BODECHTEL, G. “Anatomie, Physiologie, Pathologie u. Klinik der zentralen Anteile des vegetativen Nervensystems", in Fortschr. d. Neurol. u. Psychiatrie, 7, 295-329, 1935.

23 BOGAERT, L. VAN. "Étude d'un syndrome infundibulaire dont les crises de narcolepsie périodique $s^{\prime}$ accompagnent d'hypothermie, d'olygurie relative et d'un syndrome vagotonique d'origine centrale", in Annales de Médecine, 26, 146-161, 1929.

24 BOK, S. T. "Der Einfluss der in den Furchen u. Windungen auftretenden Krümmungen der Grosshirnrinde auf die Rindenarchitektur", in Zeitschr. i. d. ges. Neurol. u. Psychiatrie, 121, 682-750, 1929.

25 BOSS, M. "Die psychische Dynamik der Schlafkur bei Schizophrenen", in Schw. Arch. f. Neurol. u. Psychiatrie, 36, 209-220, 1935.

26 BOVEN, W. "L’hérédité des affections schizophréniques" (XLème Congr. des Méd. alién. et neurol. de France et des Pays de langue française, 20, 25-VII-1936 - Rapport de Psychiatrie), in Annales médicopsychologiques, 94, II, 267-269, 1936.

27 BRAUNMÜHL, A. von. "Über Stammganglienveränderungen bei Pickscher Krankheit.", in Zeitschr. f. d. ges. Neurol. u. Psychiatrie, 124, 212-21, 1930.

28 BRUCHANSK, N. "Zur Frage der Abgrenzung der Schizophreniegruppe", in Zeitschr. f. d. ges. Neurol. u. Psychiatrie, 143, 746-58, 1933.

29 BUCY, P. "Areas 4 and 6 of the cerebral cortex and their projection systems", in Arch. of Neurol. and Psychiatry, $35,1396-9,1936$. 
30 BYCHOWSKI, G. "Certain problems of Schizophrenia in the light of cerebral pathology", in Journ. of Nerv. and Mental Dis., 81, 280 298, 1935.

31 CENI, C. Cervello e funzioni materne. 2 vol., 195, Torino/Genova (Lattes), 1922. ."Das Gehirn und seine antagonistischen neuro-vegetativen Reaktions-Erscheinungen", in Schw. Arch. f. Neurol. u. Psychiatrie, 36, 241-6, 1935; e 37, 1-15, 1936.

CHEN, K. K.; SCHMIDT, C. F. "Acción y aplicación clínica de la efedrina", in Journ. of the Americ. Medic. Ass., edición esp., 16, 437-443I, 1926.

DEMOLE, V. "Pharmacodynamie et centres du sommeil. Mise en évidence des composantes anatomiques neurovégétative basilaire et volitionnelle corticale", in Rev. Neurol., 34, 1, 850-2, 1927.

DIMITRI, V.; VICTORIA, M. "Algunas observaciones histopatológicas en una psicosis infantil con rigidez cérea y actitudes catalepticas", in La Semana medica, Buenos Aires, 1934, 1, 1897-907, separata.

37 DUNLAP, Ch. B. "The pathology of the brain in Schizophrenia" (Chapter XXII, pp. 371-81), in Schizophrenia (Dementia praecox), Association for research in nerv. and mental Disease, vol. V. New York (Hoeber), 1928. DURUP, G.; FESSARD, A. "L'électrencephalogramme de l'homme. Données quantitatives sur l'arrèt provoqué par des stimuli visuels ou auditifs". Comptes rendus de la Soc. de Biologie, Paris, 122, 756-8, 1936.

DUSSER DE BARENNE, J. G. "Selektive Abtötung der Nervenzellschichten der Grosshirnrinde. Die Methode der laminären Thermokoagulation der Rinde (mit Anhang Von H. M. Zimmermann)", in Zeitschr. f. d. ges. Neurol. u. Psychiatrie, 147, 280-90, 1933. "The disturbances after Laminar Thermokoagulation upon the local action of the motor cerebral cortex", in Brain, 57, 517-26, 1934.

41 DUSSIK, K. Th. "Aussprache der Mitteilung Ederle's", in Zeitschr. f. d. ges. Neurol. u. Psychiatrie, 158, 425-7, 1937.

42 DUSSIK, K. Th.; SAKEL, M. Ergebnisse der Hypoglykämieschockbehandlung der Schizophrenie", in Zeitschr. f. d. ges. Neurol. u. Psychiatrie, 155, 351-415, 1936.

43 ECONOMO, C. von. L'architecture cellulaire normale de l'écorce cérébrale. Trad. de L. van Bogaert. Paris, Massort, 1927. . "Der Schlaf als Lokalisationsproblem", in "Der Schlaf" herausgegeben Von D. Sarason, pp. 3854, Berlin, Lehmanns, 1929.

46 EDERLE. "Über unsere seitherigen Erfahrungen mit der Insulinschock-Behandlung der Schizophrenie" (2. Jahresvers. d. Ges. deutscher Neurol. u. Psychiater, Frankfurt a. M, 1936), Zeitschr. f. d. ges. Neurol. u. Psychiatrie, 158, 422-4, 1937.

47 FAVRE, A. "Schizophrénies et narcose prolongée", in L'Encéphale, 31, 1, 196-211, 1936.

48 FELDHOFEN, M. "Schwierigkeiten und Gefahren der Insulinschock-Behandlung der Schizophrenie", in Allg. Zeitschr. f. Psychiater, 105, 281-98, 1936.

49 FERNANDES, B. "Die konvergierende Betrachtungsweise der pathologischen Erscheinungen bei Psychosen und organischen Hirnkrankheiten" (2. Jahresvers. d. Ges. deutscher Neurol. u. Psychiater, Frankfurt a. M., 1936). Zeitschr. f. d. ges. Neurol. u. Psychiatrie, 158, 316-321, 1937.

50 FILIMONOFF, I. N. "Motorische Anfälle bei Erkrankungen des extrapyramidalen Systems", in Zeitschr. f. d. ges. Neurol. u. Psychiatrie, 97, 504-14, 1925.

51 __. "Ein Fall mit eigenartiger extrapyramidalen motorischen Anfällen", in Zeitschr. f. d. ges. Neurol. u. Psychiatrie, 111, 251, 1927.

52 FISCHER, M. H.; LÖWENBACH, H. "Cardiazol als Weckmittel im Tierversuch", in Klin. Wochenschrift, 13, 1401, 1934.

53 FOERSTER, 0. "Die Pathogenese des epileptischen Krampfanfalles" (16. Jahresvers. d. Gesellsch. deutscher Nervenärtzte, Düsseldorf, 1926). Zentralbl. f. d. ges. Neurol. u. Psychiatrie, 44, 746-4, 776-8, 1926.

$54 \ldots$ _ PENFIELD, W. “Der Narbenzug am und im Gehin bei traumatischer Epilepsie in seiner Bedeutung für das Zustandekommen der Anfälle und für die Bekämpfung derselben", in Zeitschr. f. d. ges. Neurol. u. Psychiatrie, 125, 475, 1930.

55 FRIEDLAENDER, K. "Insulinschockbehandlung der Schizophrenie", in Psychiatr.-neurol. Wochenschrift, 1936, 38, 520. (Zentralbl. f. d. ges. Neurol. u. Psychiatrie, 83, 329, 1937).

56 FROSTIG, J. "Beitrag zur Phänomenologie der autistischen Gestalts u. Wortneubildung", in Zeitschr. f. d. ges. Neurol. u. Psychiatrie, 125, 700-33, 1930. 
57 FÜNFGELD, E. “Über anatomische Untersuchungen bei Dementia praecox mit besonderer Berücksichtigung des Thalamus opticus", in Zeitschr. f. d. ges. Neurol. u. Psychiatrie, 124, 411-63, 1930. "Bemerkungen zur Histopathologie der Schizophrenie" (2. Jahresvers. d. Ges. deutscher Neur. u. Psychiater, Frankfurt a. M., 1936). Zeitschr. f. d. ges. Neurol. u. Psychiatrie, 158, 232-4, 1937. Encephalitis epidemica", in Allg. Zeitschr. f. Psychiatrie, 91, 471-81, 1929.

GLAUS, A. "Über Kombination Von Schizophrenie und Epilepsie", in Zeitschr. f. d. ges. Neurol. u. Psychiatrie, $135,450-500,1935$.

61 GORODISSKAJA, G. I.; DROBOWA, G. “Über die chemische Topographie des Gehirns. IV. Mitt.: Stickstoff u. Phosphor der Grosshirninde der Embryonen des Menschen", in Soviet. Psiconevr, (Russ.), 1936. (Zentralbl. f. d. ges. Neurol. u. Psychiatrie, 78, 639, 1936).

62 GOZZANO, M. "Bioelektrische Erscheinungen bei der Reflexepilepsie", in Journ. f. Psychol. u. Neurol., 47, 24, 1936.

63 GREVING, R. "Die zentralen Anteile des vegetativen Nervensystems in Band IV (Nervensystem) d. "Handbuch der mikroskop. Anatomie des Menschen" herausgeg. Von W. v. Möllendorff. Berlin, Springer, 1928.

64 GRIMALDI, L.; TOMMASINO, A. "Terapia da schock insulinico nella schizophrenia", in Schizophrenie, 5, 127-30, 1935 (Zentralbl. f. d. ges. Neurol. u. Psychiatrie, 79, 523, 1936).

65 GRUHLE, H. W. "Schizophrenie", in Band IX, Handb. der Geisteskrankheiten, herausgeg. Von 0. Bumke. 1-30, 135-210, 705-13. Berlin, Springer, 1932.

66 GRÜNBAUM, A. A. “Experimentelles zur Lehre Von systematischen Zusammenhang der motorischen Erscheinungen. (Provokation einiger pseudocerebellärer u. subkortikaler Symptome bei Kranken u. Gesunden)", in Zeitschr. f. d. ges. Neurologie u. Psychiatrie, 120, 286-339, 1928.

67 GULLOTTA, S. "Interruzione della sindrome catatonica", in Riv. di Patol. nerv. e mentale, 40, 241-57, 1932. .Narcosi, catatonia ed epilessia provocate sperimentalmente mediante la corrente elettrica", in Riv. Sperim. di Freniatria, 58, 417-24, 1934. "La cura della schizofrenia con la provocazione di convulsioni epilettiche", in Riv. Sperim. di Freniatria, 60, 510-20, 1936.

70 HASAMA, Bun-ichi. "Über die Veränderungen der Eletrophänomene am Zentralnervensystem bei Äthernarkose. Electro-corticogramm, Electro-medullogramm, Electro-spinogramm", in Naunyn-Schmiedebergs Archiv, 179, 234-42, 1935 (Zentralbl. f. d. ges. Neurol. u. Psychiatrie, 79, 272, 1935). "Über die Wirkung des Pikrotoxins auf d. Grosshirnrinde im Aktionsstrombilde", in Jap. J. med. Sci., Trans. IV. Pharmacol, 8, 1935. (Zentralbl. f. d. ges. Neurol. u. Psychiatrie, 80, 561, 1936).

72 HECHST, B. "Klinisch-anatomische Beiträge zur zentralen Regulation des Schlaf-Wachseins", in Arch. f. Psychiatrie, 87, 505-25, 1929. (Zentralbl. f. d. ges. Neurol. u. Psychiatrie, 54, 489, 1930). "Gehirnanatomische Untersuchung eines Hingerichteten. Zugleich Beitrag z. Histopathologie der Schizophrenie", in Arch. f. Psychiatrie, 89, 131-76, 1929. (Zentralbl. f. d. ges. Neurol. u. Psychiatrie, 56, 418, 1930).

75 HEDENBERG, S. "Die Schizophrenie und die neueren histopathologischen Erfahrungen", in Svensk. Läkartidn. (Schwed.), 1935, 1249-57 (Zentralbl. f. d. ges. Neurol. u. Psychiatrie, 79, 205, 1936).

76 HERRMANN, G.; WODACH, E. "Epileptische Anfälle nach Schädeltrauma m. besonderen Stirnhirnmechanismen", in Zeitschr. f. d. ges. Neurol. u. Psychiatrie, 98, 59-79, 1925.

77 HESS, W. R. "Über die Wechselbeziehungen zwischen psychischen u. vegetativen Funktionen", in Schw. Archiv f. Neurol. u. Psychiatrie, 15, 260-77; 16, 37-55 e 285-306, 1925.

78 D'HOLLANDER, De Greeff; ROUVROY, Ch. "Les lésions cérébrales dans la démence précoce", in Journ. Belge de Neurol. et de Psychiatrie, 29, 643-61, 1929.

79 JELLIFFE, S. E. "The mental pictures in schizophrenia and in epidemic encephalitis" (Chapter XIV, p. 204-53) in Schizophrenia (Dementia praecox), New York, Hoeber, 1928.

80 JOSEPHY, H. "Beiträge zur Histopathologie der Dementia praecox", in Zeitschr. f. d. ges. Neurol. u. Psychiatrie, $87,394-48,1923$. "Dementia praecox (Schizophrenie)", in Band XI, Handbuch d. Geisteskrankheiten, herausgeg. “Normale u. pathologische Anatomie der vegetativen Zentren des Zwischenhirns, des 
Sympathikus u. Parasympathikus", in Handbuch der Inneren Sekretion, herausgeg. Von Max Hirsch, Band I, 662-708, Leipzig, Kabitzsch, 1932.

83 KEESER, E.; KEESER, J. “Über die Lokalisation des Veronals, der Phenyläthyl- u. Diathylbarbitursäure im Gehirn. I. Mitt.", in Arch. f. experim. Pathol. u. Pharmakol., 125, $251-6,1927$ (Zentralbl. f. d. ges. Neurol. u. Psychiatrie, 49, 216, 1928). . "Über den Nachweis Von Koffein, Morphim u. Barbitursäurederivaten im Gehirn. II. Mitt.", in

Arch. f. experim. Pathol. u. Pharmakol., 127, 230-5, 1928 (Zentralbl. f. d. ges. Neurol. u. Psychiatrie, 50, $350,1928)$. .Über die Verteilung der Diäthylbarbitursäure im Gehirn”, in Arch. f. experim. Pathol. u.

Pharmakol., 179, 226-8, 1935 (Zentralbl. f. d. ges. Neurol. u. Psychiatrie, 79, 272, 1936).

KISIMOTO, K. "Beiträge zur Encephalographie der Schizophrenie, einschl. der Resultate der fraktionierten Liquoruntersuchungen u. der Einflüsse der Encephalographie auf das vegetative Nervensystem", in Folia Psych. et Neurol. japonica (Zentralbl. f. d. ges. Neurol. u. Psychiatrie, 81, 69, 1936).

87 KLAESI, J. “Über Somnifen, eine medikamentöse Therapie schizophrener Aufregungszustände” (Schweizer Verein. f. Psychiatrie, Zürich, 1920), Arch. f. Neurol. u. Schw. Arch. f. Neurol. u. Psychiatrie, 8, 131-4, 1921.

88 KLEIST, K. Gehirnpathologie. Leipzig, Barth, 1934. . "Leitvortrag über Gehirnpathologie und Klinik der Persönlichkeit und Körperlichkeit" (59. Wandvers. d. südw. Neurol.u. Psychiater, Baden-Baden, 1934), Archivf. Psychiatrie, 103, 301-9, 1935, separata.

.Bericht über die Gehirnpathologie in ihrer Bedeutung für Neurologie und Psychiatrie" (2. Jahresvers. d. Ges. deutscher Neurol. u. Psychiater, Frankfurt a. M., 1936), Zeitschr. f. d. ges. Neurol. u. Psychiatrie, 158, 159-93, 334-40, 1937, separatas.

91 KORNMÜLLER, A. E. "Bioelektrische Charakteristica architektonischer Felder der Grosshirnrinde", in Psychiatr. neurol. Wochenschr., 34, 25-6, 1932 (Zentralbl. f. d. ges. Neurol. u. Psychiatrie, 63, 577, 1932). . "Bioelektrische Erscheinungen architektonischer Felder. Eine Methode der Lokalisation auf der Grosshirnrinde" (21. Jahresvers. d. Gesellsch. deutscher Nervenärtzte, Wiesbaden, 1932), Zentralbl. f. d. ges. Neurol. u. Psychiatrie, 65, 156-8, 1933. . "Architektonische Lokalisation bioelektrischer Erscheinungen auf der Grosshirnrinde. I. Mitt. Untersuchungen am Kaninchen bei Augenbelichtung", in Journ. f. Psychol. u. Neurologie, 44, 447-59, 1932. . "Die bioelektrischen Erscheinungen der Grosshirnrinde", in Fortschr. der Neurol. u. Psych. 5, 419-41, 1933. . "Die Ableitung bioelektrischer Effekte architektonischer Rindenfelder vom uneröffneten Schädel", in Journ. f. Psychol. u. Neurologie, 45, 172-84, 1933. . "Zur Physiologie u. Pathologie der Grosshirnrinde auf Grund bioelektrischer Untersuchungen" (II. . "Zur Frage der spezifischen Wirkung Von Pharmaca und Von Noxen auf das Zentralnervensystem", in Psychiatr.-neurol.Wochenschr., 38, 343-4, 1936. Congresso internac. de Neurologia, Londres, 1935)", Zentralbl. f. d. ges. Neurol.u. Psychiatrie, 1935. . "Lokalisationslehre oder Ganzheit des Zentralnervensystems?" (2. Jahresvers. der Gesellsch. deutscher Neurol. u. Psychiater, Frankfurt a. M., 1936), Zeitschr. f. d. ges. Neurol.u. Psychiatrie, 158, 244-6, 1937.

99 _. Die bioelektrische Erscheinungen der Hirnrindenfelder. Leipzig, Thierne, 1937.

100 KORNMÜLLER, A. E.; TÖNNIES, J. F. “Registrierung der zpezifischen Aktionsströme Von architektonischen Rindenfeldern mittels des Tönniesschen Neurographen", in (21. Jahresvers. d. Ges. deutscher Nervenärtzte, Wiesbaden, 1932), Zentralbl. f. d. ges. Neurol. u. Psychiatrie, 65, 177, 1933.

101 KROLL, F. W. "Zur Phylogenese des Krampfanfalls", in Zeitschr. f. d. ges. Neurol. u. Psychiatrie, 153, 590-9, 1935.

102 _. “Über das Vorkommen Von übertragbaren krampferzeugenden Stoffen im Hirn krampfender Tiere", in Zeitschr. f. d. ges. Neurol. u. Psychiatrie, 143, 780-93, 1933.

103 _ _Über das Vorkommen Von übertragbaren krampferzeugenden Stoffen im Hirn während des epileptischen Anfalles bei Mensch und Tier", in Zeitschr. f. d. ges. Neurol. u. Psychiatrie, 145, 739-48, 1933. 104 . "Über das Vorkommen Von übertragbaren schlaferzeugenden Stoffen", in Zeitschr. f. d. ges. 
Neurol. u. Psychiatrie, 146, 208-18, 1933.

105 KRÜGER, L. "Beitrag zur Frage der Schizophrenie-Behandlung nach Von Meduna", in Psychiatr.-neurol. Wochenschr., 38, 135-7, 1936 (Zentralbl. f. d. ges. Neurol. u. Psychiatrie, 80, 491, 1936).

106 KÜHN. "Über Anfälle bei konstitutioneller Hypoglykümie" (59. Wandvers. d. Südw. Neurol. u. Psychiater, Baden-Baden, 1934), Zentralbl. f. d. ges. Neurol. u. Psychiatrie, 75, 719, 1935.

107 KÜPPERS, E. "Die psychologische Einheitlichkeit der Schizophrenie", in Schw. Arch. f. Neurol. u. Psychiatrie, 26, 103-4, 1930.

108 __ "Aussprache der Mitteilung Ederle's" (2. Jahresvers. d. Ges. deutscher Neurol. u. Psychiater, Frankfurt a. M., 1936), Zeitschr. f. d. ges Neurol. u. Psychiatrie, 158, 425, 1937.

109 LANDA-CLASS, R.; MAIMAN, R. "Beiträge zur chemischen Topographie des Gehirns", in Issl. bol. fiz.-chim. dinam. nerv. proc. (Russ.), 1932, 94-5, (Zentralbl. f. d. ges. Neurol. u. Psychiatrie, 70, 36, 1933).

110 LANGE, J. "Grundsätzliche Erörterungen zu Kleits hirnpathologischen Lehren" (2. Jahresvers. d. Gesellsch. deutscher Neurol. u. Psychiater, Frankfurt a. M., 1936), Zeitschr. f. d. ges. Neurol. u. Psychiatrie, 158, 247-51, 1937.

111 LANGELÜDDECKE, A. "Über die differentialdiagnostische Bedeutung der Cardiazolkrämpfe", in Zeitschr.f. d. ges. Neurol. u. Psychiatrie, 156, 203-10, 1936.

112 LANGFELDT, G. "Die Insulinbehandlung der Schizophrenie", in Psychiatr. neurol. Wochenschr., 38, 483-4, 1936 (Zentralbl. f. d. ges. Neurol. u. Psychiatrie, 83, 329, 1937).

113 LEHMANN-FACIUS. "Liquoruntersuchungen bei destruktiven Erkrankungen des Nervensystems, besonders bei Schizophrenie" (2. Jahresvers. d. Gesellsch. deutscher Neurol. u. Psychiater, Frankfurt a. M., 1936) Zeitschr. f. d. ges. Neurol. u. Psychiatrie, 158, 109-15, 1937.

114 LEMKE, R. “Untersuchungen über die soziale Prognose der Schizophrenie unter bes. Berücksichtigung des encephalographischen Befundes", in Archiv. f. Psychiatrie, 104, 89-136, 1935 (Zentralbl. f. d. ges. Neurol. u. Psychiatrie, 79, 205, 1936).

115 __ "Über Beziehungen zwischen Verlauf der Schizophrenie u. ihrem encephalographischem Bild", in Zeitschr. f. d. ges. Neurol. u. Psychiatrie, 158, 443, 1937.

116 LEONHARD, K. "Weitere Behandlungserfolge mit Atropin bei Manie u. Ergotamin bei Melancholie", in Zeitschr. f. d. ges. Neurol. u. Psychiatrie, 151, 331-45, 1934.

117 _. Die defektschizophrenen Krankheitsbilder. Leipzig, Thieme, 1936.

118 LESCHKE, E. "Erkrankungen des vegetativen Nervensystems", in Handbuch der Inneren Sekretion, herausgeg. Von M. Hirsch. Band III, I. H., 1019-182. Leipzig, Kabitzsch, 1928.

119 LHERMUTE, J. Le sommeil. Paris, Armand Collin, 1931.

120 . "La syphilis diencéphalique et les syndromes végétatifs qu'elle conditionne. Étude clinique", in Annales de Médecine, 33, 272-91, 1933.

121 LHERMUTE, J.; TOURNAY, A. "Rapport zur le sommeil normal et pathologique" (VIII' Réunion internat. de Neurologie, 1927), in Rev. Neurol., 1927, I, 751-829.

122 LOOMIS, A. L.; HARVEY E. N.; HOBART, C. "Potential rhythms of the cerebral cortex during sleep", in Science (N. Y.), 1935, I, 597-8 (Zentralbl. f. d. ges. Neurol. u. Psychiatrie, 80, 305, 1936).

123 __. "Further observations on the potential rhythms of the cerebral cortex during sleep", in Science (N.Y.), 1935, 11, 198-200 (Zentralbl. f. d, ges. Neurol. u. Psychiatrie, 80, 582, 1936).

124 LUTZ, J. "Über die Dauerschlafbehandlung in der Psychiatrie", in Zeitschr. f. d. ges. Neurol. u. Psychiatrie, 123, 91-121, 1929.

125 LUXENBURGER, H. “Untersuchungen zur Frage der Korrelation von schizophrener Anlage u. Widerstandsschwäche gegen die tuberkulöse Infektion", in Zeitsclir. f. d. ges. Neurol. u. Psychiatrie, 122, 74-89, 1929.

126 MARINESCO, G.; SAGER, 0.; KREINDLER, A. "Recherches experimentales sur le mécanisme du sommeil", in Bull. de l'Acad. de Médecine de Paris, 100, 753-6, 1928.

127 _ _Recherches anatomocliniques sur la localisation de la fonction du sommeil", in Rev Neurol., $1929,11,481-98$.

128 __ "Beiträge zu einer allgemeinen Theorie des Schlafes", in Zeitschr. f. d. ges. Neurol. u. Psychiatrie, 122, 23-47, 1929.

129 _. "Experimentelle Untersuchungen zum Problem des Schlafmechanismus", in Zeitschr. f. d. ges. Neurol. u. Psychiatrie, 119, 277-306, 1929. 
130 MARINESCO, G.; FAÇON, E.; BRUCHET, A.; PANNESCO-PADEANO, A. "La forme narcoleptique de l'hypoglycémie (Contribution à l'étude du syndrome neurologique de l'hypoglycémie)", in Annales de Médecine, 33, 177 84, 1933.

131 MAYER-GROSS, W. "Primäre u. sekundäre Symptome in der Schizophrenie", in Zeitschr. f. d. ges. Neurol. u. Psychiatrie, 124, 647-72, 1930. in Band IX, Schizophrenie, Handbuch der Geisteskrankheiten herausgeg, Von 0. Bumke, pp. 112-34; 293-605. Berlin, Springer, 1932.

133 MEDUNA, L. von. "Über experimentelle Kampferepilepsie", in Archiv f. Psychiatrie, 102, 333-9, 1934 (Zentralbl. f. d. ges. Neurol.u. Psychiatrie, 74, 435, 1935).

134 _. "Versuche über die biologische Beeinflussung des Ablaufes der Schizophrenie. Kampfer- u. Cardiazolkrämpfe", in Zeitschr. f. d. ges. Neurol. u. Psychiatrie, 152, 235-62, 1935. "Die Konvulsionstherapie der Schizophrenie", in Psychiatr.-neurol. Wochenschr., 37, 317-9, 1935 (Zentralbl. f. d. ges. Neurol. u. Psychiatrie, 77, 687-8, 1935).

136 . Die Konvulsionstherapie der Schizophrenie. Halle a. S., Marhold, 1937.

137 MEERLO0, A. M. "Die paradoxe u. wechselnde Wirkung der Barbitursäurederivate (Ihre Verhalten hei Encephalitikern)", in Zeitschr. f. d. ges. Neurol. u. Psychiatrie, 143, 722-45, 1933.

138 MENNINGER, K. A. "The schizophrenic syndrome as a product of acute infectious disease" (Chapter XIII, p. 182203), in Schizophrenia (Dementia praecox). Ass. for research in nervous and mental dis., vol. V, New York, Hoeber, 1928.

139 MINKOWSKI, E. "La schizophrénie (Ver Chap. V. "La portée thérapeutique de la notion de schizophrénie", pp. 244-65). Paris, Payot, 1927.

140 MISCOLCZY, D. "Über das anatomische Korrelat der Schizophrenie”, in Zeitschr. f. d. ges. Neurol. u. Psychiatrie, 147, 509-54, 1933.

141 . Die örtliche Verteilung der Gehirnveränderungen bei der Schizophrenie" (2. Jahresvers. d. Gesellsch. deutscher Neurol. u. Psychiater, Frankfurt a. M., 1936), Zeitschr. f. d. ges. Neurol. u. Psychiatrie, 158, 203-8, 1937.

142 MOLITOR, H.; PICK, E. P. "Pharmakologie der Schlafmittel”, in Der Schlaf, herausgeg. Von D. Sarason, pp. 7692. Berlin, Lehmanns, 1929.

143 MOREL, F. "L'audition dans I'aphasie sensorielle", in L'Encéphale, 30, 11, 533-53, 1935, separata.

144 MÜLLER, G. "Zur Frage der Altersbestimmung histologischer Veränderungen im menschlichen Gehirn unter Berücksichtigung der örtlichen Verteilung", in Zeitschr. f. d. ges. Neurol. u. Psychiatrie, 124, 1-112, 1930.

145 "Anfülle bei schizophrenen Erkrankungen", in Allg. Zeitschr. f. Psychiatrie, 93, 235-40, 1930.

146 MÜLLER, M. "Die Dauernarkose mit Somnifen in der Psychiatrie. Ein Übe-blick", in Zeitschr. f. d. ges. Neurol. u. Psychiatrie, 96, 653-82, 1925.

147 . "Le traitement de la schizophrénie parl'insuline", in Annales médico-psychol., 94, 11, 649-57, 1936.

148 MÜNZER, F. Th. "Beiträge zur Pathologie u. Pathogenese der Dementia praecox (Schizophrenie)", in Zeitschr.f. d. ges. Neurol. u. Psychiatrie, 103, 73-132, 1926.

149 ORLAND0, R. "Síndromes neurológicos atípicos de la paralisia general", in Rev. Neurol. de Buenos Aires, 1, 32 $67,1936$.

150 PACHECO E SILVA, A. C. “Da patogenia do sono, particularmente na encefalite epidêmica”, in Bol. da Soc. de Med. e Cir. de São Paulo, 1921, 246-8.

151 PENDERGRASS, E. P. "Interpretation of encephalographic observations", in Arch. of Neurol. and Psychiatry, 23, 946-85, 1930.

152 PEREYRA-KÄFER, J. "Gliobastoma multiforme del lóbulo temporal isquierdo", in Rev. neurol. de Buenos Aires, 1, 387-406, 1937.

153 PETERS, G. "Gibt es eine pathologische Anatomie der Schizophrenie? (2. Jahresvers. d. Geselisch. deutscher Neurol. u. Psychiater, Frankfurt a. M., 1936), Zeitschr. f. d. ges. Neurol. u. Psychiatrie, 158, 324-9, 1937.

154 PIKE, F. H.; ELSBERG, C. A.; CULLOCK, W. S.; CHAPPELL, M. N. "The problem of localization in experimentally induced convulsions", in Arch. of Neurol. and Psychiatry, 23, 847-67, 1930.

155 PINTO CESAR, E. "Nosologia psiquiátrica em novas bases", in Memórias do Hospital de Juquerí, São Paulo, 910, 17-112, 1932-1933

156 POPPELREUTER, W. “Die planmässige Gestaltung der Obduktion Kriegsverletzter. Ihre Bedeutung für 
Wissenschaftund Forschung", in Zeitschr. f. d. ges. Neurol. u. Psychiatrie, 153, 27-36, 1935.

157 PÖTZL, 0. "Der Schlaf als psychisches Problem. IV: Zur Physiologie des Schlafes", in Der Schlaf, herausgeg. von Sarason, pp. 24-38; 54-64. Berlin, Lehmanns, 1929.

158 RANGE, R. W. "Der Einfluss Von Narkotika auf die Tätigkeit der Gehirnrinde des Kaninchens. Bioelektrische Untersuchungen. 1. Mitt.", in Journ. f. Psychol. u. Neurologie, 46, 364, 1934.

159 REDLICH, E. "Über Narkolepsie", in Zeitschr. f. d. ges. Neurol. u. Psychiatrie, 95, 256-70, 1925.

160 "Epilegomena zur Narkolepsiefrage" (Aus d. Nachlass v. Prof. Redlich, herausgeg. Von J. Wilder), in Zeitschr. f. d. ges. Neurol. u. Psychiatrie, 136, 128-73, 1931.

161 RIEBELING, C.“Beiträge zur chemischen Topographie des Gehirns, insbesondere bei Psychosen”, in Zeitschr. f. d. ges. Neurol. u. Psychiatrie, 158, 375-80, 1937.

162 ROSANOFF, A. J.; HANDY, L. M.; PLESSET, I. R.; BRUSH, S. “The etiology of so-calied schizophrenic psychoses", in Am. Journ. of Psychiatry, 91, 725-62, 1934.

163 ROSE, M. "Über die elektive Schichtenerkrankung der Grosshirnrinde bei Geisteskrankheiten", in Journ. f. Psychol. u. Neurologie, 47, 1-23, 1936.

164 ROUSSY, G.; MOSINGER, M. "Le tuber cinereum et son rôle dans les principales fonctions du métabolisme", in Annales de Médecine, 33, 193-238, 1933.

165 __. "Le sub-thalamus et les formations sub-thalamo-mesencéphaliques", in Rev. Neurol., 1935, I, $637-61$.

166 ___ "Rapports anatomiques et physiologiques de l'hypothalamus et de l'hypophyse", in Annales de Médecine, 33, 301-24, 1933.

167 ROWE, St. N. "Localisation of the sleep mechanism", in Brain, 58, 21-48, 1935.

168 SAKEL, M. "Neve Beltandlung der Morphiumsucht (Eine Insulinkur beseitigt die Abstinenzerscheinungen durch Ausgleich des während der Entziehung gestörten Gleichgewichtes im vegetativert Nervensystem)", in Zeitschr. f. d. ges. Neurol. u. Psychiatrie, 143, 506-34, 1933.

169 . Neve Behandlungsmethode der Schizophrenie. Wien, Peries, 1935.

170 _Zur Methodik der Hypoglykämie-Behandlung Von Psychosen", in Wiener medizin. Wochenschr., 1936, 11, 1278-82, (Zentralbl. f. d. ges, Neurol. u. Psychiatrie, 83, 627, 1937).

171 SANZ IBANEEZ, J.; RODRIGUEZ PEREZ, A. P. “Les altérations histopathologiques dans I"encéphalite guanidinique' expérimentale. Encéphalose avec réaction gliale proliferative", in Arch. internat. de Neurologie, 55, pp. IIIXIV, 1936.

172 SARKISSOW, S. A. "Zur Frage der Zentren des vegetativen Nervensystems", in Journ. f. Psychol. u. Neurologie, 35, 28-41, 1927.

173 SCHARFETTER, H.; SEEGER, Th. (mit einem Beitrag Von W. Ludwig). "Zur Klinik der kataplektischen Anfälle", in Zeitschr. f. d. ges. Neurol. u. Psychiatrie, 153, 37-89, 1935.

174 SCHMID, H. "Zur Histopathologie der Sakelschen Hypoglykämieschock-Behandlung der Schizophrenie", in Schw. medizin. Wochenschr., 1936, 11, 960-1, (Zentralbl. f. d. ges. Neurol. u. Psychiatrie, 83, $328,1937)$.

175 SCHNEIDER, C. "Weitere Beiträge zur Lehre Von der Pickschen Krankheit", in Zeitschr. f. d. ges. Neurol. u. Psychiatrie, 120, 340-84, 1928.

176 SCHOLZ, W. "Über die Entstehung des Hirnbefundes bei der Epilepsie", in Zeitschr. f. d. ges. Neurol. u. Psychiatrie, 145, 471-515, 1933.

177 SCHWARTZ, PH.; COHN, H. "Eigenschaften der Ausdehnung anatomischer Erkrankungen im Zentralnervensystem", in Zeitschr. f. d. ges. Neurol. u. Psychiatrie, 126, 1-93, 1930.

178 SEREJSKI, M. J. "Zur Fragestellung über Umfang u. Klassifikation der schizophrenen Reaktionen", in Zeitschr. f. d. ges. Neurol. u. Psychiatrie, 152, 310-23, 1935.

179 SEREJSKI, M. J.; FELDMANN, E. S. "Die Anwendung der Dauernarkose in der Psychiatrie", in Zeitschr. f. d. ges. Neurol. u. Psychiatrie, 157, 246-76, 1937.

180 SEREJSKI, M. J.; TOPSTEIN, R. "Pathochemie des Gehirns. 1. Mitt.: Progressive Paralyse”, in Zeitschr. f. d. Neurol. u. Psychiatrie, 141, 57-64, 1932.

181 SILVEIRA, A. "Teoria das funções cerebrais segundo Augusto Comte" (Comun. à Assoc. Paulista de Medicina, 5XI-1936)

182 _. "Lesões casuais e lesões sistemáticas do cérebro nas doenças mentais", in Arq. da Assist. Geral a Psicopatas, São Paulo, II, 191-217, 1937. 
183 SMITH, W. K. "The extent and structure of the electrically excitable cerebral cortex in the frontal lobe of the dog", in Journ. comp. Neurol., 62, 421-42, 1935, (Zentralbl. f. d. ges. Neurol. u. Psychiatrie, 79, 438, 1936).

184 SOMOGYI, I.; von ANGYAL, L. “Das Vorkommen Von schizophrenen Bildern bei der progressiven Paralyse und deren Bedeutung", in Zeitschr. f. d. ges. Neurol. u. Psychiatrie, 146, 145-66, 1933.

185 SPIELMEYER, W. "Zur Pathogenese der örtlichen elektiven Gehirnveränderung", in Zeitschr. f. d. ges. Neurol. u. Psychiatrie, 99, 756-79, 1926.

186 "Kreislaufstörungen und Psychosen", in Zeitschr. f. d. ges. Neurol. u. Psychiatrie, 123, 536-73, 1926.

187 _. "Die Anatomie der Psychosen", in Band XI, Hand buch der Geisteskrankheiten, herausgeg. Von 0. Bumke. Berlin, Springer, 1930. (especialmente pp. 1-41). . "The problem of the anatomy of schizophrenia", in Journ. of Nerv. and Mental Disease, 72, 241-4, 1930.

189 STEBLOW, E. M. “Das Problem der Klassifikation der Epilepsieformen”, in Zeitschr. f. d. ges. Neurol. u. Psychiatrie, 142, 335-49, 1932.

190 STEINER, G. "Anatomisches", in Band IX, Die Schizophrenie, Handbuch der Geisteskrankheiten, herausgeg. Von 0. Bumke. Berlin, Springer, 1932.

191 STERN, K. "Der Zellaufbau des menschlichen Mittelhirns. Mit einem histopathologischen Anhang”, in Zeitschr.f. d. ges. Neurol. u. Psychiatrie, 154, 521-98, 1935.

192 STIEF, A.; TOKAY, L. “Beiträge zur Histopathologie der experimentellen Insulinvergiftung”, in Zeitschr. f. d. ges. Neurol. u. Psychiatrie, 139, 434-61, 1932.

193 _. "Weitere experimentelle Untersuchungen über die cerebrale Wirkung des Insulins", in Zeitschr. f. d. ges. Neurol. u. Psychiatrie, 153, 561-72, 1935.

194 TANCREDI, F.; PINTO DE TOLEDO, L. "Provas experimentais para o diagnóstico da epilepsia”, in Arq. da Assist. Geral a Psicopatas, S. Paulo.

195 TCHALISSOFF, M. A. "Zur chemischen Topographie der Hirnrinde. I. Mitt.: Lactacidogengehalt der Hirnrinde bei Schizophrenen", in Zeitschr. f. d. ges. Neurol. u. Psychiatrie, 142, 85-97, 1932.

196 TCHALISSOFF, M. A.; WOLFSON, N. M.; AROUTINOFF, D. N. “Métabolisme intermédiaire du cerveau chez les schizophrènes", in L'Encéphale, 31, 11, 174-202, 1936.

197 TEENSTRA, P. E. M. "Die Behandlung schizophrener Psychosen mit Insulinschock", in Nederl. Tïdschr. Gennesk. (Hol), 1936, 17-24 (Zentralbl. f. d. ges. Neurol. u. Psychiatrie, 80, 490, 1936)

198 TÖNNIES, J. F. “Der Neurograph, ein Apparat zur unmittelbar sichtbaren Registrierung bioelektrischer Erscheinungen (21. Jahresvers. d. Gesellsch. deutscher Nervenärtzte, Wiesbaden, 1932), Zentralbl. f. d. ges. Neurol. u. Psychiatrie, 65, 158-9, 1932.

199 _. "Die Ableitung bioelektrischer Effekte vom uneröffneten Schädel. Physikalische Behandlung des Problems", in Journ. f. Psychol. u. Neurologie, 45, 154-71, 1933.

200 TRENDELENBURG, W. Örtliche "Entstehung und Verlauf des experimentellen Epilepsieanfalls" (16. Jahresvers. d. Gesellsch. deutscher Nervenärtzte, Düsseldorf, 1926), Zentralbl. f. d. ges. Neurol. u. Psychiatrie, 44, 766, 1926.

201 VITELLO, A. "Sui rapporti della schizophrenia con l'epilessia", in Ospedal. Psichiatrico, 4, 216-39, 1936. (Zentralbl. f. d. ges, Neurol. u. Psychiatrie, 83, 82, 1936).

202 VOGT, C.; VOGT, 0. "Erkrankungen der Grosshirninde im Lichte der Topistik, Pathoklise u. Pathoarchitektonik", in Journ. f. Psychol. u. Neurologie, 28, 1-171, 1922.

203 VOGT, M. “Die Verteilung von Arzneistoffen auf verschiedene Regionen des Zentralnervensystems. Zugleich ein Beitrag zu ihrer quantitativen Mikrobestimmung. II: Chinin und Mezcalin; V: Barbitursäurederivate; VI: Chloralhydrat", in Arch. f. experim. Pathologie, 178, 560-76; 603-27; 628-38, 1935 (Zentralbl. f. d. ges. Neurol. u. Psychiatrie, 79, 22, 24, 275, 1936).

204 VOLLAND. "Über motorische Phänomene bei verblödeten Epileptikern", in Zeitschr. f. d. ges. Neurol. u. Psychiatrie, 98, 775-88, 1925.

205 WAHLMANN. "Vorläufige Mitteilung über Konvulsionstherapie der Psychosen", in Psychiatr.-neurol. Wochenschr., $38,78-9,1936$.

206 WALKER, A. E. "The Thalamus in relation to the cerebral cortex", in The Journ. of Nerv. and Mental Dis., 85, 249-61, 1937. 
207 WEESE, H. "Moderne Schlafmittelbehandlung und Basisnarkose", in Schmerz, 9, 1-16, 1936, (Zentralbl. f. d. ges. Neurol. u. Psychiatrie, 81, 298, 1936).

208 WICHERT, FR. "Ein Beitrag zur Frage des Vorhandenseins und der Lokalisation der vegetativen Zentren in der Grosshirninde", in Journ. f. Psychol. u. Neurologie, 37, 693-712, 1929.

209 WOSSKRESSENSKI, S. “Über den Basen-, insbesondere Ammoniakstickstoffgehalt des Grosshirns bei verschiedenen Psychosen", in Zeitschr. f. d. ges. Neurol. u. Psychiatrie, 98, 751-4, 1925.

210 YAHN, M.; ARRUDA, J. "0 tratamento pelo coma insulínico em dois casos de esquizofrenia catatônica", in Arq. da Assist. Geral a Psicopatas, S. Paulo, II, 99-121, 1937.

211

"A glicemia no tratamento pelo coma insulínico", in Arq. da Assist. Geral a Psicopatas, S. Paulo, II, 179-90, 1937.

212 ZWEIG, H. “Das Schlafproblem", in Zentralbl. f. d. ges. Neurol. u. Psychiatrie, 55, 353-73, 1930.

Trabalhos publicados depois de pronta a presente comunicação e aqui citados em notas:

213 ANGYAL, L. VON; GYÁRFÁS, K. "Über die Cardiazol-Krampfbehandlung der Schizophrenie", in Arch. f. Psychiatrie, 106, pp. 1-12, 1936, (Zentralbl. f. d. ges. Neurol. u. Psychiatrie, 84, p. 649, 1937).

214 DUENSING, FR. "Darf der Cardiazol-Krampfanfall diagnostisch verwertet werden?", in Münch. medizin. Wochenschr., 84, 1011-5; 27/Juni/1937.

215 ENKE, W. "Arzneimittelbehandlung in der Psychiatrie", in Fortschr. d. Neurol. u. Psychiatrie, 9, 225-49, Juni/ 1937.

216 EWALD, G. "Über moderne Behandlungsfragen in der Psychiatrie", in Münch. medizin. Wochenschr., 84, 101921, 27/Juni/1937.

217 KÜPPERS, E. "Die Insulinbehandlung der Schizophrenie", in Deutsche Medizinische Wochenschrift, 1937 (Cit. in M. Müller, April, 1937).

218 LANGELÜDDECKE, A. "Die diagnostische Bedeutung experimentell erzeugter Krämpfe", in Deutsche medizin. Wochenschr., 39, II, 1588-90, 1936 (Zentralbl. f. d. ges. Neurol. u. Psychiatrie, 83, 639, 1/Mai/ 1937).

219 MAGENAU, 0. "Über innere Gemeinsamkeit der verschiedenen Schizophreniebehandlungsmittel und-methoden", in Psychiatr.-neurol. Wochenschrift, 39, 83-8; 20 Febr. 1937 (Cit. in M. Müller, April, 1937).

220 MARQUES DE CARVALHO, H.; SILVA, P. A. "Tratamento convulsivante na esquizofrenia” (Comunicação à Assoc. Paulista de Medicina, 5-IV-1937), in Arq. da Assist. Geral a Psicopatas, S. Paulo.

221 MÜLLER, M. "Insulin- u. Cardiazolschockbehandlung der Schizophrenie", in Fortschr. d. Neurol. u. Psychiatrie, 9, 131-66, April, 1937

222 PAP, Z. von. "Erfahrungen mit der Insulinschockbehandlung hei Schizophrenie", in Monatsschr. f. Psychiatrie, 94, 318-46, 1937 (Zentralbl. f. d. ges. Neurol. u. Psychiatrie, 85, 553, 15/Juli/1937).

223 SCHEUHAMMER, P.; WISSGOTT, L. "Erfahrungen mit der Cardiazolbehandlung der Schizophrenie", in Psychiatr.neurol. Wochenschr., 39, 286-88, 26/Juni/1937.

224 STIEF, A. "Der Wirkungsmechanismus der sogenannten Konvulsionstherapie mit besonderer Berücksichtigung der Insulinschockbehandlung", in Psychiatr.-neurol. Wochenschr., 39, 225-9, 22/Mai/1937. 